JEA N-PA U L F I T O U S S I

Observatoire Français des Conjonctures Économiques

DAVID JESTAZ

Observatoire Français des Conjonctures Économiques

EDMUND S. PHELPS

Columbia University

G YLFI ZOEGA

Birkbeck College

\title{
Roots of the Recent Recoveries: Labor Reforms or Private Sector Forces?
}

FROM THE MID-1970s to the mid-1980s, most of the industrial economies of the Organization for Economic Cooperation and Development (OECD) suffered a sharp slide in economic activity, as measured both by employment in relation to the labor force and by male labor force participation in relation to the working-age population. This decline sparked new structuralist modeling of the determinants of employment and supplied an empirical record for testing the models. Some consensus has now emerged on the main mechanisms and causal forces behind the deep slump. ${ }^{1}$

In the 1990s, however, structural recovery became evident in many OECD countries. Structural unemployment in Ireland, the Netherlands, and the United Kingdom appears to have improved in the first half of the 1990s and again in the second half. Australia, Canada, Denmark, New Zealand, Spain, and the United States showed structural gains in the second half. ${ }^{2}$

1. A convergence of views among several scholars on the role played by a small set of macroeconomic forces and institutions is evident in the recent symposium on unemployment in the Economic Journal. See Nickell (1998), Phelps and Zoega (1998), and Madsen (1998).

2. The United States, however, failed to achieve full recovery, since a fixed-weight index of the unemployment rates in the four educational groups is still short of its 1965 and 1970 levels. 
Finland, Norway, and Sweden have begun to rebound from the loss of export markets and banking crises early in the 1990s. For the other OECD members, any recovery during the 1990 s was too little and too late to make much difference in their record for the decade as a whole. Austria, France, Germany, Greece, Italy, and Switzerland actually suffered net setbacks over the decade, and Belgium and Portugal made scant progress.

In searching for the principal causes of the great slump-the shift of equilibrium unemployment rates onto higher paths in the 1980sresearchers had some idea where to look. Unemployment rates in the OECD countries had risen roughly in unison from the mid-1970s to the mid-1980s — any deviations were mostly in the timing. Thus all the favored candidates to explain the phenomenon were OECD-wide shocks. Models of the equilibrium employment path set out by Edmund Phelps, with their emphasis on the profitability of business assets and the reward to work relative to workers' other support, pointed to five common shocks during that period. ${ }^{3}$ The first, emerging in the 1970 s, was reduced expectations of productivity growth leading to increases in the effective cost of capital. The second, in the early 1980s, was an increase in the expected world real rate of interest, which likewise raised the effective cost of capital. The third was increases in income and services from workers' private assets. The fourth was increases in benefits from social entitlements relative to after-tax wage levels, resulting from the 1970s productivity slowdown and from the growth of the welfare state in the 1960s and 1970s. The fifth shock was the hikes in the world real price of oil during the 1970s. ${ }^{4}$ A model by Richard Layard, Richard Jackman, and Stephen Nickell pointed to an important role for new or expanded institutions in the postwar era, especially in Europe, such as unemployment insurance benefits and job protections, which heightened the sensitivity of unemployment to shocks. ${ }^{5}$

Accounting for the selective and uneven recoveries that began in the 1990 s is a different sort of problem. Did the recovering countries experi-

3. Phelps (1994).

4. Phelps (1994) and Phelps and Zoega (1996) found econometric support for the importance of these forces. Further evidence supporting the effect of changes in real interest rates, productivity growth rates, or both can be found in Blanchard (1997), Blanchard and Wolfers (2000), Elmeskov, Martin, and Scarpetta (1998), Nickell and Layard (1999), and Phelps and Zoega (1998). Recent evidence confirming the role of wealth can be found in Phelps and Zoega (1998).

5. Layard, Nickell, and Jackman (1991). 
ence some shock or other development that the nonrecovering countries did not? Or was there an OECD-wide shock or trend that powered recovery in some economies but was somehow blocked from doing so in the nonrecovering economies? In either case, do the causal forces and mechanisms fall within the compass of existing theory, and can they be accommodated by existing models?

The first hypotheses to be examined in this paper credit progress in the recovering countries to their adoption of structural reforms and blame the continued stagnation elsewhere to a failure to enact similar programs. One such hypothesis, developed by Nickell and the OECD Secretariat, points to reforms in labor policy by several OECD members. In this thesis, anti-market labor policies sowed the seeds of the huge rise in unemployment in Europe, and the remedy lies in reversing those policies. The chief areas for reform in this view are unemployment insurance benefits, which are often generous and of long duration; the high density and wide coverage of unions in wage setting; and employment protection laws that lengthen the average wait of an unemployed worker for a job. ${ }^{6}$

Of course, good economic policy is crucial for good economic performance. Yet it may be that these particular reforms had little or no effect. Perhaps planting more deeply the institutions of capitalism, or instituting or expanding employment subsidies for those earning low wages, would be vastly more effective in reducing unemployment (even if such reforms are more costly in other dimensions). Europeans who value their welfare state protections want to know whether the reduction in unemployment obtained by scaling these protections back is sufficient compensation for the loss of security.

The second part of the paper examines some hypotheses that invoke monetary factors to explain cross-country differences in employment performance. These hypotheses deviate to varying degrees from the nonmonetary approach of the structuralist models. We first test the thesis of Jean-Paul Fitoussi and others that tight money in France, Italy, and certain other candidates for European Monetary Union (EMU) operated in the 1990 s, or at least the middle years of the decade, to depress employment

6. See Nickell and Layard (1999), Elmeskov, Martin, and Scarpetta (1998), and OECD Economic Outlook, June 1999. Union density is the proportion of the work force unionized, and union coverage the proportion to which union wages apply. 
far below its structural equilibrium path. ${ }^{7}$ This is related to Laurence Ball's more radical thesis that prolonged monetary tightness in some OECD economies in the early or mid-1990s produced a hysteresis effect, leaving today's equilibrium unemployment path on a higher track than it would otherwise be on. ${ }^{8}$

One conspicuous shock has been rather widespread in the OECD economies, namely, the sensational rise of share prices and market capitalization on most organized stock exchanges from New York to Helsinki. Much of this surge has been fueled, it appears, by high expectations about future profits from the new information technologies-in short, the new economy. That a rise in firms' valuation of the business assets in which they invest - employees, customers, and various kinds of tangible capital — would generally boost the equilibrium path of employment was a clear implication of Phelps's theoretical framework. And arguably, the rise in firms' market capitalization reflects a rise in the value their managers place on investing in such assets, present or future-or, vice versa, a rise in market capitalization induces managers to raise the value they assign to investing in such assets. A loose relationship in U.S. data between share prices and employment growth has given some empirical support to this argument. ${ }^{9}$

The last part of this paper will try to gauge the strength of the average relationship between stock market valuations and employment growth in the OECD countries. It will then proceed to investigate whether disparities in the size of the stock market boom from country to country are broadly consistent with the selectivity, unevenness, and timing of the recent recoveries. It is worth trying to determine whether the economies that have not yet recovered have had a smaller rise in their stock markets, properly measured, or whether some factors have blocked or delayed them from responding to their stock market rise to the same degree as the average OECD country.

The first section of the paper introduces our framework. A necessary exercise here is to verify that not all the recent recoveries (and failures to recover) are well explained by the garden-variety market forces on which

7. Fitoussi (1998). Of course, the contention of some that regular and equal-sized devaluations would have kept employment bounded above its equilibrium path is radically counter to the structuralist view.

8. Ball (1999).

9. Phelps (1999). 
we have previously placed our emphasis. These include the world real rate of interest, national productivity growth rates, and the after-tax reward to work relative to workers' nonwage support, such as the imputed income from durable goods that workers own and the social benefits that they or their relatives receive.

\section{Two Baseline Unemployment Equations}

Our past empirical tests of these structuralist ideas have viewed macroeconomic forces as acting upon the valuations of various business assets in two ways. The first is through the cost of capital. The second is through the profits on business assets and thus possibly through expected future profits.

In the models, the long-term gross cost of capital is the domestic longterm expected real interest rate. The correct measure, as first emphasized by Christopher Pissarides, is the gross cost net of the expected long-term growth rate, $g$, of the productivity of labor. ${ }^{10}$ In our model, the reciprocal of this (net) cost of capital is a reasonable trial proxy for the shadow price of a trained employee and of other business assets, given the "level" from which the expected stream of profits from such an asset starts. ${ }^{11}$

For econometric purposes, our measure of the gross cost of capital is an external measure, the average long-term real interest rate in the Group of Seven (G-7) countries. This rate is dubbed the world real interest rate and denoted $r^{*} \cdot{ }^{12}$ Figure A1 in appendix A juxtaposes the path of the net cost of capital, $r^{*}-g$, against the path of the unemployment rate for each of the G-7 countries except Japan. The increases in this variable between the

10. The argument by Pissarides (1990) that the expected $g$ enters into the capitalization of business assets was used in some theoretical exercises by Phelps (1994). Our empirical work began using the world real interest rate $r^{*}$ without $g$, but we brought $g$ in upon realizing the importance of the productivity slowdown for understanding the slump, especially on the Continent. See Hoon and Phelps (1997).

11. The reciprocal gives the present discounted value of a stream of profits that starts at one and grows at a constant rate $g$. If each trained employee produced that stream of gross profit, after deducting the interest on fixed capital and customers he or she will have to work with (given the current cost of capital), that reciprocal would indeed be the market value of such an employee.

12. This rate is the average of the real long-term interest rate calculated from the yield on ten-year government bonds and the rate of price inflation in the following four quarters. 
early 1970s and the mid-1980s were huge in every country, although not equal and synchronous, and preceded large increases in the national unemployment rate. It is thus plausible that the slowdowns in labor productivity and the elevation of world interest rates (figure A2 in appendix A) played a major role in the rise of unemployment to its 1980s peak.

One can also see, in many OECD economies, a major turnaround in this variable in recent years, owing to higher domestic productivity growth as well as a somewhat lower $r^{*}$. Improved productivity performance in the 1990s may account for some part of the recovery under way in many of the OECD economies. Tables A1 and A2 in appendix A show the changes from period to period in the average rate of growth of the (HodrickPrescott-smoothed) productivity of labor, defined as GDP per person employed. The productivity growth slowdown in the 1970s is evident in all of the countries except Norway.

Yet the recent productivity speedup is very selective. Among the countries that experienced a marked reduction in unemployment in the 1990s, Australia, Denmark, Ireland, and New Zealand have also enjoyed a recovery in the rate of productivity growth. So has the United States when productivity is calculated from the recent GDP data revision (tables A1 and $\mathrm{A} 2$ are based on the unrevised data). The main exceptions are the Netherlands and the United Kingdom, which, although strongly recovering, do not show a marked productivity speedup. So, although surely no single causal variable would vary from country to country so as to fully account for the diverse experience of the OECD countries in the past decade, improvements in employment and in productivity growth have tended to coincide.

These differing evolutions of productivity growth - and hence in the net cost of capital-across countries are significant. To illustrate, we compare data for one of the clearest success stories, Ireland, with those for Italy, where unemployment has been persistently high. In both countries the spectacular rise in the cost of capital in the late 1970s or early $1980 \mathrm{~s}$ preceded a long climb of the unemployment rate (figure 1). In Ireland, however, the recovery of the cost of capital to levels of the 1960s and early 1970s was followed by a good recovery of employment, whereas the partial recovery of capital costs in Italy led to little or no employment recovery there.

The association between unemployment rates and the cost of capital apparent in figure 1 is consistent with our theoretical framework. Such an 
Figure 1. Unemployment and the Net Cost of Capital in Ireland and Italy, 1960-99

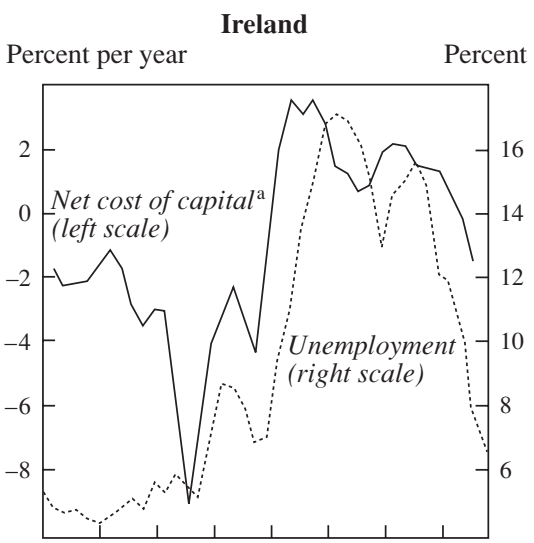

1965197019751980198519901995
Italy

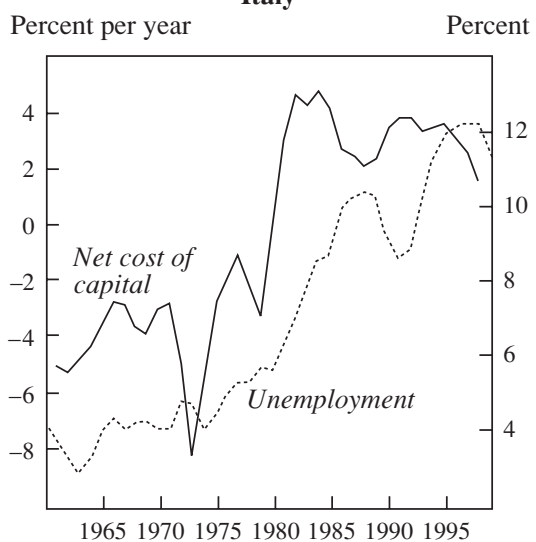

Source: Authors' calculations using OECD data.

a. Defined as $r^{*}-g$, or the world interest rate minus the expected long-term growth rate of labor productivity.

apparent association may be compatible with alternative models, but we believe that the strength of this association is a feature that any model of unemployment has to take into account.

Clearly the cost of capital is not by itself a sufficient explanatory variable. The value placed upon a trained employee and upon the other assets of a business depends on the "level" from which the expected stream of profits from such an asset starts, not just on the net cost of capital used to value that stream. Therefore we require, alongside the cost of capital, one or more explanatory variables that impact on profitability through their influence on the zero-profit curve or the wage curve.

One such variable in our models is workers' income or services from wealth, both private and social, relative to the reward to their work. The income from social wealth, $y^{S}$, includes social insurance and social assistance benefits; the income and services from private wealth, $y^{W}$, include not only the income from stocks and bonds issued by domestic firms but also that from holdings of domestic public debt and net overseas assets as well as the services of consumer durables. An increase in such income and services would increase quitting (and shirking and absenteeism) at any given unemployment rate, which would add to unit costs of production and thus reduce the valuation of employees. This in turn would slow firms' 
hiring and thus the growth of employment. Similarly, a decrease in productivity or an increase in tax rates on labor, by increasing income and services from wealth relative to after-tax pay, would exacerbate quitting and thus lower employee valuations. (Thus the level of productivity and the tax rate on labor matter for unemployment through their effect on the after-tax wage relative to the income and services from workers' wealth. ${ }^{13}$ ) The effect of this income-to-net pay variable on the unemployment rate may be captured by introducing as a surrogate the total level of income from private wealth and benefits per worker as a ratio to the productivity of labor, denoted $\tilde{y}^{W}+\tilde{y}^{S}$, multiplied by the ratio of before-tax to after-tax wages. We call this compound variable normalized nonwage support. ${ }^{14}$ The other profitability variable that we have used is the world real price of energy, but we will not pause to discuss that variable here.

Figures A3 and A4 in appendix A show trends in income and services from private wealth and social spending, respectively, juxtaposed against the unemployment rate in each of the G-7 countries except Japan. The patterns are far from identical from country to country. Yet there is a tendency among these countries for normalized nonwage support to show a cumulative rise starting in the middle of the 1970s and continuing for many years. In those countries where productivity accelerated in the 1990s, however, normalized nonwage support tends to decline sooner or later. Figure 2 again shows data for Ireland and Italy. The Irish data, which begin in 1977, show a recent downward trend, thanks to a strong acceleration of productivity, whereas in Italy no such trend is visible in recent years.

Our previous work estimated equations explaining either the normalized increase in employment or the level of the unemployment rate, with the lagged unemployment rate always among the explanatory variables. Equation 1 is a stripped-down version of a typical example of these equations, reestimated here using a nineteen-country OECD sample for the period 1960-98 ${ }^{15}$ :

13. The econometric formulation here leaves open the possibility that, in the long run, wealth will have adjusted so as to restore the ratio of the after-tax wage to wealth to some long-run level that is independent of tax rates and of the cumulative labor augmentation from past technical progress.

14. The derivation is laid out in appendix B.

15. The countries are Australia, Austria, Belgium, Canada, Denmark, Finland, France, Germany, Ireland, Italy, Japan, the Netherlands, New Zealand, Norway, Portugal, Spain, Sweden, the United Kingdom, and the United States. 
Figure 2. Unemployment and Nonwage Support in Ireland and Italy, 1960-99

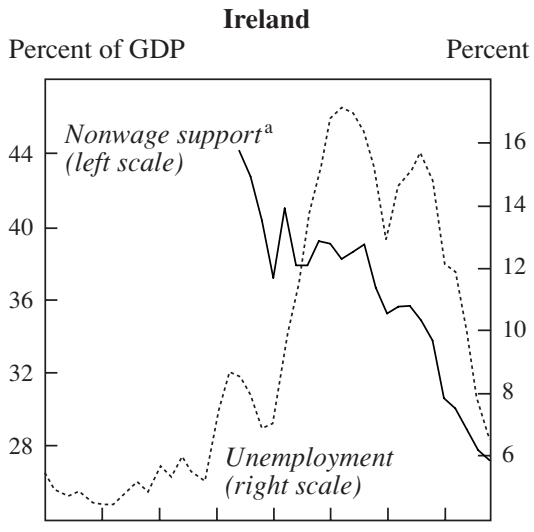

1965197019751980198519901995
Italy

Percent of GDP Percent

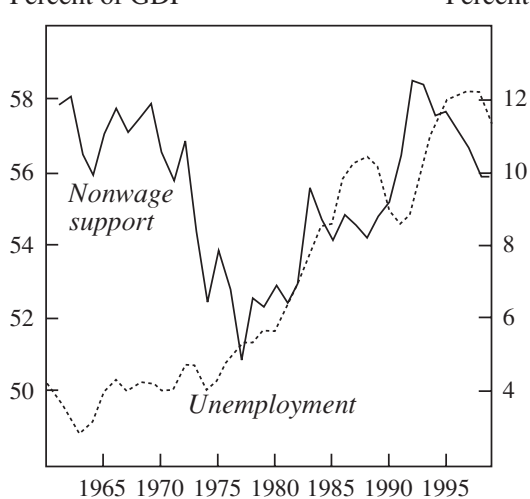

Source: OECD data.

a. Defined as $y^{W}+y^{S}$, or income and services from private wealth (from private financial holdings and consumer durables) plus income from social wealth (such as social insurance and social assistance benefits).

$$
\begin{aligned}
u_{i t}= & \alpha_{i}+\mu_{i} u_{i t-1}+\phi_{i}^{1} r_{t-1}^{*}+\phi_{i}^{2} g_{i t-1}+\phi_{i}^{3} p_{t-1}^{\text {oil }} \\
& +\phi_{i}^{4}\left(\tilde{y}_{i t-1}^{W}+\tilde{y}_{i t-1}^{S}\right) \frac{1+\tau_{i t-1}^{p}}{1-\tau_{i t-1}^{D}}+\gamma_{i} \Delta \pi_{i t}+\varepsilon_{i t} .
\end{aligned}
$$

Here $u$ is the rate of unemployment, $r^{*}$ is the world real rate of interest, $g$ is the (smoothed) rate of change in labor productivity, ${ }^{16} p^{\text {oil }}$ is the real price of oil, $\widetilde{y}^{W}+\widetilde{y}^{S}$ is the ratio of total nonwage support (per worker in the labor force) to labor productivity, $\tau^{D}$ is the rate of direct household taxes, $\tau^{P}$ is the rate of payroll taxes, and $\pi$ is the rate of price inflation. ${ }^{17}$

In an effort to control for "effective demand" shocks, we include the change in the rate of inflation, following Layard, Nickell, and Jackman. ${ }^{18}$ The idea is that if unemployment changes because of movements in aggre-

16. This is a Hodrick-Prescott-smoothed rate of change of labor productivity defined as real GDP per employed worker. The smoothing parameter has a value of 100 .

17. We include a dummy variable for Finland and Germany in the 1990s, both of which experienced shocks due to the disintegration of the Soviet bloc, and for Portugal in the 1970 s, when a wave of immigration temporarily raised unemployment in that country. Even so, our stripped-down baseline regressions do not satisfactorily track the Portuguese unemployment rate.

18. Layard, Nickell, and Jackman (1991) and Phelps (1994). 
gate demand, this is likely to be reflected in changes in the rate of price inflation. The inclusion of an inflation shock term may thus remove from the unemployment series such business-cycle movements, leaving changes in the natural rate to be explained by the remaining regressors.

We first estimate equation 1 for each country separately, without imposing any cross-country restrictions. This is important to do because, once we start constraining coefficients to take the same value across countries, the possibility arises that a significant relationship for some of the countries will create the illusion of a sample-wide relationship. That is, if the equation fits for one group of countries but does not fit for another, the panel estimation may yield significant results due only to the inclusion of the first group. The results are shown in table A3 in appendix A. The coefficients on the interest rate $\phi^{1}$ and oil prices $\phi^{3}$ are generally positive, whereas those on productivity growth $\phi^{2}$ and the inflation term $\gamma$ tend to be negative. However, the coefficient of income from private wealth $\phi^{4}$ does not have the same consistent pattern.

We now impose cross-country restrictions. We constrain $\phi^{1}, \phi^{2}, \phi^{3}$, and $\phi^{4}$ to have identical values across countries up to a factor of proportionality, $\theta_{i}$, so that their ratios to one another are the same in all countries:

$$
\begin{aligned}
u_{i t}= & \alpha_{i}+u_{i t-1}+\theta_{i}\left(\phi^{1} r_{t-1}^{*}+\phi^{2} g_{i t-1}+\phi^{3} p_{t-1}^{*}+\phi^{4}\left(\tilde{y}_{i t-1}^{w}+\tilde{y}_{i t-1}^{s}\right) \frac{1+\tau_{i t-1}^{p}}{1-\tau_{i t-1}^{D}}\right) \\
& +\gamma_{i} \Delta \pi_{i t}+\varepsilon_{i t} .
\end{aligned}
$$

The idea behind this restriction is that the differences in the effect of shocks across countries lie largely in the degree of rigidity of the real wage, which can be captured by the parameter $\theta_{i}$.

Results from four versions of this equation appear in table 1 . The first version (column 1-1) omits both elements of nonwage support; normalized income from private wealth $\left(\widetilde{y}^{W}\right)$ is then added to the equation in column 12. Next, in column 1-3, we add to the column 1-1 specification the comparable variable that measures the level of social spending or transfers per worker, also normalized by productivity $\left(\tilde{y}^{S}\right)$. Finally, column 1-4 includes both nonwage support variables. ${ }^{19}$

19. We have an unbalanced panel when we add income from private wealth because of missing observations at the beginning of the period. 
Table 1. Regressions for the Constrained Baseline Equation ${ }^{\mathrm{a}}$

\begin{tabular}{|c|c|c|c|c|}
\hline \multirow[b]{2}{*}{ Independent variable } & \multicolumn{4}{|c|}{ Equation } \\
\hline & $1-1$ & $1-2^{\mathrm{b}}$ & $1-3^{\mathrm{c}}$ & $1-4^{\mathrm{c}}$ \\
\hline World real rate of interest ${ }^{\mathrm{d}}$ & $\begin{array}{l}0.04 * * \\
(1.96)\end{array}$ & $\begin{array}{l}0.02 * * \\
(3.08)\end{array}$ & $\begin{array}{l}0.01 * * \\
(2.41)\end{array}$ & $\begin{array}{l}0.01 * * \\
(2.10)\end{array}$ \\
\hline Domestic rate of productivity growth ${ }^{\mathrm{e}}$ & $\begin{array}{l}-0.18 * * \\
(2.13)\end{array}$ & $\begin{array}{c}-0.06^{* * *} \\
(3.03)\end{array}$ & $\begin{array}{c}-0.03 \\
(1.39)\end{array}$ & $\begin{array}{c}-0.04 * * \\
(2.16)\end{array}$ \\
\hline Real price of oil ${ }^{\mathrm{f}}$ & $\begin{array}{l}2.39 * * \\
(2.58)\end{array}$ & $\begin{array}{l}0.78 * * \\
(3.74)\end{array}$ & $\begin{array}{l}0.50 * * \\
(3.28)\end{array}$ & $\begin{array}{l}0.80 * * \\
(3.45)\end{array}$ \\
\hline Income from private wealth ${ }^{g}$ & & $\begin{array}{c}0.65 \\
(1.48)\end{array}$ & & \\
\hline Social spending ${ }^{\text {h }}$ & & & $\begin{array}{l}3.29 * * \\
(2.91)\end{array}$ & \\
\hline Nonwage support ${ }^{\mathrm{i}}$ & & & & $\begin{array}{c}2.44 \\
(2.95)\end{array}$ \\
\hline \multicolumn{5}{|c|}{$\begin{array}{l}\text { Source: Authors' regressions using OECD and Citibase data for 1960-98 (OECD, 1982, 1987; OECD Economic Outlook, } \\
\text { June 1999). } \\
\text { a. Results are for equation } 2 \text {. The dependent variable, the unemployment rate, is the OECD standardized rate. Unemployment, } \\
\text { interest rates, and growth rates are expressed as percentages in the equations. The sample consists of nineteen OECD countries } \\
\text { except where noted otherwise. } t \text {-statistics are in parentheses. ** denotes significance at the } 5 \text { percent level. } \\
\text { b. Australia is omitted from the sample. } \\
\text { c. Australia and New Zealand are omitted from the sample. } \\
\text { d. Real interest rates are calculated from quarterly data on the annual yield on one-year government bonds and the rate of } \\
\text { price inflation in the subsequent four quarters where the price deflator is used. The world real rate of interest } r * \text { is calculated as the } \\
\text { average of real rates in the G-7 countries. } \\
\text { e. Defined as the rate of growth of real GDP per employed worker, smoothed using the Hodrick-Prescott filter with a smooth- } \\
\text { ing parameter of } 100 \text {. } \\
\text { f. Measured as the ratio of the U.S. producer price index (PPI) for crude petroleum to the overall U.S. PPI. } \\
\text { g. Calculated as the ratio of income from property per worker in the labor force to real GDP per employed worker. } \\
\text { h. Calculated in the same way as income from private wealth using social security benefits. Payroll taxes are equal to the ratio of } \\
\text { social security contributions to the wage bill, and direct taxes are defined as the ratio of direct household taxes to household income. } \\
\text { i. The sum of income from private wealth and social spending. }\end{array}$} \\
\hline
\end{tabular}

The coefficients on real interest rates, productivity growth, and oil prices are all correctly signed and significant. ${ }^{20}$ The nonwage support variable is also significant, although its nonwage income component is less so. ${ }^{21}$

Table 2 reports, for the baseline equation in column 1-1 of table 1 , the estimates of our fixed effects variable $\alpha_{i}$, the sensitivity coefficients $\theta_{i}$, and the persistence parameters $\mu_{i}$, in addition to the coefficient on the inflation shock $\gamma_{i}$. We note that many of the "success" economies are highsensitivity, low-persistence economies: among these are the United King-

20. We experimented with changing the smoothing parameter used to calculate trend productivity growth. When it took the values 50,150 , and 250 , the coefficient on productivity growth was, respectively, -0.19 (with a $t$-statistic of 2.17 ), $-0.23(2.21)$, and -0.25 (2.26).

21. Note that the sample changes when we add nonwage income (Australia drops out) and again when social spending is added (both Australia and New Zealand are omitted). 
Table 2. Further Estimation Results for the Constrained Baseline Equation ${ }^{\text {a }}$

\begin{tabular}{|c|c|c|c|c|c|c|}
\hline Country & $\begin{array}{l}\text { Constant } \\
\left(\alpha_{i}\right)\end{array}$ & $\begin{array}{c}\text { Lagged } \\
\text { unemployment } \\
\text { rate }\left(\mu_{i}\right)\end{array}$ & $\begin{array}{c}\text { Sensitivity } \\
\text { coefficient } \\
\left(\theta_{i}\right)\end{array}$ & $\begin{array}{l}\text { Coefficient on } \\
\text { price inflation } \\
\qquad\left(\gamma_{i}\right)\end{array}$ & $R^{2}$ & Adjusted $R^{2}$ \\
\hline Australia & $\begin{array}{c}0.71 \\
(2.13)\end{array}$ & $\begin{array}{c}0.84 \\
(14.04)\end{array}$ & 1.00 & $\begin{array}{c}-5.77 \\
(0.66)\end{array}$ & 0.93 & 0.91 \\
\hline Austria & $\begin{array}{c}0.20 \\
(1.76)\end{array}$ & $\begin{array}{c}0.96 \\
(36.93)\end{array}$ & $\begin{array}{c}0.32 \\
(2.15)\end{array}$ & $\begin{array}{l}-6.29 \\
(1.94)\end{array}$ & 0.98 & 0.98 \\
\hline Belgium & $\begin{array}{c}1.26 \\
(2.80)\end{array}$ & $\begin{array}{c}0.83 \\
(18.45)\end{array}$ & $\begin{array}{c}1.53 \\
(2.26)\end{array}$ & $\begin{array}{c}-3.46 \\
(0.60)\end{array}$ & 0.98 & 0.97 \\
\hline Canada & $\begin{array}{c}1.77 \\
(3.37)\end{array}$ & $\begin{array}{c}0.70 \\
(9.46)\end{array}$ & $\begin{array}{c}1.32 \\
(2.08)\end{array}$ & $\begin{array}{r}-19.18 \\
(1.82)\end{array}$ & 0.89 & 0.87 \\
\hline Denmark & $\begin{array}{c}0.75 \\
(2.37)\end{array}$ & $\begin{array}{c}0.84 \\
(15.68)\end{array}$ & $\begin{array}{c}1.10 \\
(1.84)\end{array}$ & $\begin{array}{l}-8.78 \\
(0.92)\end{array}$ & 0.94 & 0.93 \\
\hline Finland & $\begin{array}{c}1.51 \\
(4.07)\end{array}$ & $\begin{array}{c}0.58 \\
(7.95)\end{array}$ & $\begin{array}{c}0.90 \\
(1.68)\end{array}$ & $\begin{array}{l}-8.16 \\
(1.03)\end{array}$ & 0.95 & 0.93 \\
\hline France & $\begin{array}{c}0.70 \\
(3.08)\end{array}$ & $\begin{array}{c}0.92 \\
(34.39)\end{array}$ & $\begin{array}{c}0.69 \\
(2.11)\end{array}$ & $\begin{array}{c}-1.42 \\
(0.30)\end{array}$ & 0.99 & 0.98 \\
\hline Germany & $\begin{array}{c}0.69 \\
(3.11)\end{array}$ & $\begin{array}{c}0.81 \\
(18.12)\end{array}$ & $\begin{array}{c}0.82 \\
(2.15)\end{array}$ & $\begin{array}{r}-19.69 \\
(2.34)\end{array}$ & 0.98 & 0.97 \\
\hline Ireland & $\begin{array}{c}1.51 \\
(2.56)\end{array}$ & $\begin{array}{c}0.86 \\
(21.08)\end{array}$ & $\begin{array}{c}1.91 \\
(2.28)\end{array}$ & $\begin{array}{c}-1.55 \\
(0.25)\end{array}$ & 0.96 & 0.95 \\
\hline Italy & $\begin{array}{c}0.56 \\
(2.35)\end{array}$ & $\begin{array}{c}0.95 \\
(30.77)\end{array}$ & $\begin{array}{c}0.33 \\
(1.62)\end{array}$ & $\begin{array}{l}-8.08 \\
(2.29)\end{array}$ & 0.98 & 0.97 \\
\hline Japan & $\begin{array}{c}0.20 \\
(1.56)\end{array}$ & $\begin{array}{c}0.93 \\
(15.96)\end{array}$ & $\begin{array}{c}0.09 \\
(1.42)\end{array}$ & $\begin{array}{l}-2.24 \\
(2.21)\end{array}$ & 0.96 & 0.95 \\
\hline Netherlands & $\begin{array}{c}0.94 \\
(2.60)\end{array}$ & $\begin{array}{c}0.73 \\
(10.80)\end{array}$ & $\begin{array}{c}1.35 \\
(2.13)\end{array}$ & $\begin{array}{l}-2.26 \\
(0.45)\end{array}$ & 0.94 & 0.92 \\
\hline New Zealand & $\begin{array}{c}0.47 \\
(1.95)\end{array}$ & $\begin{array}{c}0.92 \\
(20.53)\end{array}$ & $\begin{array}{c}0.60 \\
(1.69)\end{array}$ & $\begin{array}{c}-1.05 \\
(0.44)\end{array}$ & 0.95 & 0.93 \\
\hline Norway & $\begin{array}{c}0.44 \\
(2.05)\end{array}$ & $\begin{array}{c}0.88 \\
(15.61)\end{array}$ & $\begin{array}{c}0.32 \\
(1.42)\end{array}$ & $\begin{array}{l}-7.10 \\
(1.71)\end{array}$ & 0.90 & 0.88 \\
\hline Portugal & $\begin{array}{c}2.00 \\
(3.16)\end{array}$ & $\begin{array}{c}0.61 \\
(5.95)\end{array}$ & $\begin{array}{c}-0.18 \\
(0.59)\end{array}$ & $\begin{array}{l}-4.46 \\
(1.08)\end{array}$ & 0.85 & 0.81 \\
\hline Spain & $\begin{array}{c}2.09 \\
(3.22)\end{array}$ & $\begin{array}{c}0.85 \\
(23.53)\end{array}$ & $\begin{array}{c}1.84 \\
(2.21)\end{array}$ & $\begin{array}{r}-10.67 \\
(1.28)\end{array}$ & 0.98 & 0.98 \\
\hline Sweden & $\begin{array}{c}0.31 \\
(1.43)\end{array}$ & $\begin{array}{c}0.93 \\
(15.82)\end{array}$ & $\begin{array}{c}0.25 \\
(1.01)\end{array}$ & $\begin{array}{l}-3.85 \\
(0.70)\end{array}$ & 0.89 & 0.87 \\
\hline United Kingdom & $\begin{array}{c}1.23 \\
(2.85)\end{array}$ & $\begin{array}{c}0.70 \\
(12.89)\end{array}$ & $\begin{array}{c}2.41 \\
(2.39)\end{array}$ & $\begin{array}{c}-3.63 \\
(0.76)\end{array}$ & 0.96 & 0.95 \\
\hline United States & $\begin{array}{c}2.58 \\
(4.08)\end{array}$ & $\begin{array}{c}0.48 \\
(4.26)\end{array}$ & $\begin{array}{c}1.16 \\
(2.03)\end{array}$ & $\begin{array}{r}-18.71 \\
(1.73)\end{array}$ & 0.76 & 0.72 \\
\hline
\end{tabular}

Source: See table 1.

a. Results are for equation 1-1 in table $1 ; t$-statistics are in parentheses. 
$\operatorname{dom}(\theta=2.41, \mu=0.70)$, the Netherlands $(\theta=1.35, \mu=0.73)$, and the United States $(\theta=1.16, \mu=0.48)$.

Table 3 quantifies the impact of real interest rates and the productivity growth rate on unemployment. It shows both the instantaneous ("current") effect and the steady-state effect of a rise in $r^{*}$ of 5 percentage points, or 500 basis points, and a fall in the rate of trend productivity growth by 3 percentage points, for a subsample of the countries. Our world real interest rate variable rose by 5 percentage points between the 1970s and 1980s, and a slowdown in the rate of productivity growth of between 2 and 3 percentage points was not uncommon between the average of the 1960s and the average of the 1970s.

Both the instantaneous and the steady-state effects differ across countries. The magnitude of the interest rate effects is in the same ballpark as recent estimates by Blanchard and Justin Wolfers, ${ }^{22}$ but the effect of growth appears to be substantially higher. Taken together, a simultaneous rise in $r^{*}$ and fall in $g$ can account for much of the rise in average unemployment between the 1960s and the 1980s. Figure 3 plots the actual decade-to-decade change in average unemployment for recent decades against the fitted change from equation 2 for the nineteen countries in our sample. The fit is quite good for both the 1980s and the 1990s, although it is slightly less so for the latter, suggesting that the equation does not fully explain the cross-country variation in the pace of recovery.

\section{Explaining Differences Across Countries: Shocks Versus Institutions}

In our baseline regression, we estimated the value of the sensitivity coefficient $\left(\theta_{i}\right)$ as well as the country-specific fixed effects $\left(\alpha_{i}\right)$ and the persistence parameter $\left(\mu_{i}\right)$ in equation 2 . We now look to the institutional structures of these countries to explain the differences in these three parameters across countries. But note that the parameters $\theta_{i}$ and $\mu_{i}$ affect only the degree of the unemployment response to macroeconomic shocks.

Layard and coauthors hypothesized that unemployment differences across countries could be attributed to differences in the replacement ratio of unemployment benefits, their duration, union coverage and density,

22. Blanchard and Wolfers (2000). 
Table 3. Estimated Effects of Interest Rate Changes and Changes in Productivity Growth on Unemployment

Percentage points

\begin{tabular}{lccccc}
\hline & \multicolumn{5}{c}{ Change in unemployment $(\Delta u)$} \\
\cline { 2 - 6 } & France & Germany & Italy & $\begin{array}{c}\text { United } \\
\text { Kingdom }\end{array}$ & $\begin{array}{c}\text { United } \\
\text { States }\end{array}$ \\
\hline $\begin{array}{l}\text { Change in real interest rate } \\
\left.\text { ( } r^{*}\right) \text { of 5 percentage points }\end{array}$ & & & & & \\
$\quad$ Current effect & 0.15 & 0.17 & 0.07 & 0.51 & 0.25 \\
$\quad$ Steady-state effect & 1.84 & 0.92 & 1.40 & 1.55 & 0.48 \\
Change in productivity & & & & & \\
growth rate $(\Delta g)$ of & & & & & \\
-3 percentage points & 0.38 & 0.45 & 0.18 & 1.33 & 0.64 \\
$\quad$ Current effect & 4.78 & 2.38 & 3.66 & 4.03 & 1.25 \\
$\quad$ Steady-state effect & & & & &
\end{tabular}

Source: Authors' calculations based on regression results in tables 1 and 2 .

union and employer coordination in wage setting, active labor market programs, and an index of employment protection. ${ }^{23}$ We find that these variables explain around 50 percent of the variation in the $\alpha$ and $\theta$ coefficients (table 4$)$. The fixed effects $(\alpha)$ are a positive function of the replacement ratio and of union coverage and density, and a negative function of union coordination. The sensitivity to shocks $(\theta)$ is a positive function of the duration of benefits and union density and a negative function of union coordination and labor market expenditure. The table reports the results for both the instantaneous effect and, by taking into account the persistence parameter $\mu_{i}$, the steady-state effect. ${ }^{24}$

We conclude that the sign of each coefficient in the $\alpha$ and $\theta$ equations is as expected from a reading of Jorgen Elmeskov and coauthors, Layard and coauthors, and Nickell. ${ }^{25}$ These results confirm the significant effect of labor market institutions on medium-term unemployment changes. But it may not be the institutions themselves that are causing the unemployment problem, but rather an unfortunate combination of labor demand shocks and institutions.

23. Layard, Nickell, and Jackman (1991). See also Nickell and Layard (1999), from which our data come.

24 . The sensitivity and persistence parameters are strongly negatively correlated.

25. Elmeskov, Martin, and Scarpetta (1998), Layard, Nickell, and Jackman (1991), and Nickell and Layard (1999). 
Figure 3. Actual and Predicted Changes in Average Unemployment Across Decades in Nineteen OECD Countries
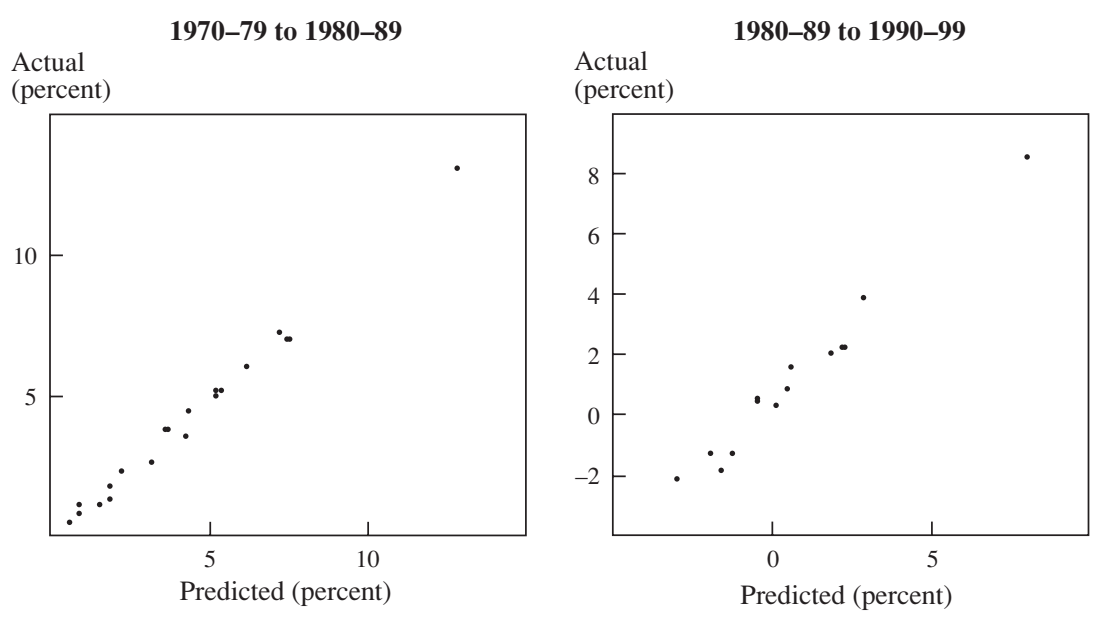

Source: Authors' calculations using OECD data.

\section{Can the Baseline Equation Account for the Diversity of Recent Experience?}

The question arises whether our simple baseline equation 2 explains, without the benefit of new ideas, the diverse experience of the OECD countries in the 1990s. To assess this, we estimated equation 2 for the period 1960-91 and then performed out-of-sample simulations and compared these with the actual pattern of unemployment during the period 1992-98. Table 5 classifies the nineteen countries in our sample according to whether the difference between the actual and the predicted unemployment rate was less than 1.5 percentage points in 1998.

In the U.S. case, unemployment in 1998 was 1.78 percentage points lower than expected, so the recent decline is not fully accounted for. In recent years Ireland has likewise done better than what one would have expected from our model, Denmark and the United Kingdom have done about as well as one would have expected, and Australia has fared somewhat worse. On the continent, France, Germany, Italy, and Spain all have done worse than expected. 
Table 4. Regressions Explaining Differences in Baseline Equation Parameters ${ }^{\mathrm{a}}$

\begin{tabular}{|c|c|c|c|c|}
\hline \multirow[b]{2}{*}{ Independent variable } & \multicolumn{2}{|c|}{ Fixed effects } & \multicolumn{2}{|c|}{ Sensitivity to shocks } \\
\hline & $\begin{array}{l}\text { Current effect } \\
\qquad\left(\hat{\alpha}_{i}\right)\end{array}$ & $\begin{array}{c}\text { Steady-state } \\
\text { effect } \\
{[\hat{\alpha} /(1-\hat{\lambda})]}\end{array}$ & $\begin{array}{l}\text { Current effect } \\
\left(\hat{\theta}_{i}\right)\end{array}$ & $\begin{array}{c}\text { Steady-state } \\
\text { effect } \\
{\left[\hat{\theta}_{i} /(1-\hat{\lambda})\right]}\end{array}$ \\
\hline Constant & $\begin{array}{c}0.13 \\
(0.33)\end{array}$ & $\begin{array}{l}3.27 \\
(1.19)\end{array}$ & $\begin{array}{c}0.81 \\
(2.66)\end{array}$ & $\begin{array}{l}4.86 \\
(2.10)\end{array}$ \\
\hline Replacement ratio & $\begin{array}{c}0.01 \\
(2.28)\end{array}$ & & & \\
\hline Duration of benefits & & & $\begin{array}{c}0.20 \\
(3.04)\end{array}$ & $\begin{array}{l}1.10 \\
(2.65)\end{array}$ \\
\hline Union density & $\begin{array}{c}0.03 \\
(3.45)\end{array}$ & $\begin{array}{l}0.05 \\
(1.45)\end{array}$ & $\begin{array}{c}0.03 \\
(5.28)\end{array}$ & $\begin{array}{c}0.11 \\
(2.20)\end{array}$ \\
\hline Union coordination & $\begin{array}{l}-0.86 \\
(3.45)\end{array}$ & $\begin{array}{l}-3.74 \\
(3.76)\end{array}$ & $\begin{array}{l}-0.68 \\
(4.86)\end{array}$ & $\begin{array}{l}-2.62 \\
(2.34)\end{array}$ \\
\hline Union coverage & $\begin{array}{l}0.35 \\
(2.26)\end{array}$ & $\begin{array}{l}2.94 \\
(2.66)\end{array}$ & & \\
\hline Labor market expenditure & & & $\begin{array}{l}-0.02 \\
(3.42)\end{array}$ & $\begin{array}{l}-0.13 \\
(1.86)\end{array}$ \\
\hline$R^{2}$ & 0.54 & 0.52 & 0.69 & 0.57 \\
\hline Adjusted $R^{2}$ & 0.41 & 0.43 & 0.61 & 0.45 \\
\hline \multicolumn{5}{|c|}{$\begin{array}{l}\text { Source: Regression results using the equation described below. } \\
\text { a. The table shows regressions of the form }\end{array}$} \\
\hline $\begin{array}{l}\text { where } x=\alpha \text { or } \theta \text {, and } Y \text { is a vector } \\
\text { benefits (the number of months at } \\
\text { between unions and employers ( } m \\
\text { expenditure on active labor marke } \\
\text { period 1983-88. } t \text {-statistics are in pa }\end{array}$ & $\begin{array}{l}\text { llowing explanator } \\
\text { enefits continue at } \\
\text { as an index where } \\
\text { s. Data are averag } \\
\text { es. }\end{array}$ & $\begin{array}{l}\text { variables: the re } \\
\text { reasonable leve } \\
\text { denotes maxim }\end{array}$ & $\begin{array}{l}\text { tr ratio, the dura } \\
\text { coverage, union } \\
\text { ination), emplo }\end{array}$ & $\begin{array}{l}\text { n of unemployment } \\
\text { nsity, coordination } \\
\text { ent protection, and } \\
\text { s in table } 2 \text { for the }\end{array}$ \\
\hline
\end{tabular}

A key question addressed in this paper is what accounts for the crosscountry differences in unemployment rates over the 1990s. We consider three types of explanations. First, there is the appeal to labor market reforms by the OECD Secretariat. This view would credit the strong reduction of unemployment in some countries to policy reforms rather than private sector market forces. There is also the New Keynesian view that cyclical downturns have a persistent effect on unemployment through some form of hysteresis, and the anti-inflationist view that some countries lowered their equilibrium unemployment path by conquering inflation. Finally, deriving from our own models' property that employment depends on the level of asset valuations, there is the empirical hypothesis that a stock market index or market capitalization series provides a proxy for those asset valuations that play a pivotal role in employment growth. The last section of this paper compares the predictions of this hypothesis with the actual data. 
Table 5. Out-of-Sample Simulations: Actual Minus Predicted Unemployment in 1998 Percentage points

\begin{tabular}{|c|c|c|c|c|c|}
\hline \multicolumn{2}{|c|}{$\begin{array}{l}\text { Unemployment lower } \\
\text { than expected }\end{array}$} & \multicolumn{2}{|c|}{ Unemployment as expected } & \multicolumn{2}{|c|}{$\begin{array}{l}\text { Unemployment higher } \\
\text { than expected }\end{array}$} \\
\hline Country & Difference & Country & Difference & Country & Difference \\
\hline Finland & -2.67 & Austria & 0.57 & Australia & 1.89 \\
\hline Ireland & -4.49 & Denmark & -0.25 & Belgium & 4.70 \\
\hline New Zealand & $-1.72^{\mathrm{a}}$ & Canada & 0.80 & France & 3.26 \\
\hline Norway & -3.32 & Japan & 1.35 & Germany & 3.59 \\
\hline \multirow{4}{*}{ United States } & -1.78 & Netherlands & -1.15 & Italy & 3.55 \\
\hline & & United Kingdom & 0.39 & Portugal & $2.63^{b}$ \\
\hline & & & & Spain & 4.30 \\
\hline & & & & Sweden & 4.38 \\
\hline
\end{tabular}

Source: Authors' calculations based on results in tables 1 and 2.

a. Estimated using data up to 1994.

b. Estimated using data up to 1996.

\section{Reforms}

\section{Labor Market Reforms}

A careful study by the OECD Secretariat has identified several countries that it regards as having accepted its proposals for labor market reform. ${ }^{26}$ The recommendations involve measures to reduce or eliminate labor and product market restrictions and regulations, to increase spending on active labor market programs, and to reduce the duration of unemployment benefits. The countries are Australia, Denmark, Ireland, the Netherlands, New Zealand, and the United Kingdom. Three recent papers describe some of these changes: ${ }^{27}$

-Apart from Australia, all of these countries either kept unchanged or reduced the generosity of the unemployment benefit system in the 1990s. But Finland, France, Germany, Spain, and Sweden, all countries usually not counted among the success stories, did the same (although later in the case of Spain).

-Denmark, Ireland, and the Netherlands also spent more than the OECD average on active labor market programs, and they increased this spending in the 1990s.

26. Elmeskov, Martin, and Scarpetta (1998).

27. Scarpetta (1996), Elmeskov, Martin, and Scarpetta (1998), and Nickell and van Ours (2000). 
-All six countries reduced the labor tax wedge in the 1990s.

-Union power was reduced in the United Kingdom in the 1980s, and in New Zealand in the 1990s. Australia and Denmark moved toward decentralization of wage bargaining. Governments in Ireland and the Netherlands introduced greater coordination with unions and employers.

-Employment protection legislation has been relaxed in Australia, the Netherlands, and the United Kingdom.

One can point to several other significant institutional reforms in the 1990s. They include the gradual reduction of the minimum wage in the United States, the increase in the amount and coverage of the U.S. earned income tax credit, and the increasing exemption of low-income households from income tax and the massive subsidies for wage supplements or for training in the Netherlands, France, and the United States.

Table 6 demonstrates the power of labor market institutions in explaining cross-country differences in average unemployment. Our equation regressing the average rate of unemployment in the 1980s against a set of institutional variables used by Nickell and Layard for the years 1983-88 is able to explain around 65 percent of the variation in unemployment. ${ }^{28}$ The signs of the institutional variables are as expected, and all the variables are significant. Unemployment disparities thus appear due to a high replacement ratio of unemployment benefits, long duration of these benefits, high coverage and density of unions, employment protection, and low coordination of unions and employers, in addition to low labor market expenditure. ${ }^{29}$

Although the importance of labor market institutions is almost universally accepted, it is also widely believed - certainly by us-that the shocks that pushed the equilibrium unemployment path to higher and higher tracks in the 1970s and 1980s were mostly of a different nature. ${ }^{30}$ We have already indicated the institutions we have emphasized in past work. Many of the labor market institutions in the OECD countries may have played a role in propagating shocks rather than originating them, since they had their origins well before the rise, beginning in the mid1970 s, in unemployment rates. ${ }^{31}$ In view of the past influence of market

28. Their ideas were introduced in Nickell and Layard (1999).

29. When Sweden is removed from the sample, however, the labor market expenditure variable becomes insignificant.

30. See Fitoussi and Phelps (1988); Phelps (1994); Phelps and Zoega (1997, 1998); Blanchard and Wolfers (2000).

31. See Krugman (1994) on this point. 
Table 6. Regressions Explaining the Unemployment Rate in the 1980s with Labor Market Institutions ${ }^{a}$

\begin{tabular}{lc}
\hline Independent variable & Estimated coefficient \\
\hline Constant & 5.02 \\
& $(2.00)$ \\
Replacement ratio & 0.12 \\
& $(2.95)$ \\
Duration of benefits & 0.79 \\
& $(2.13)$ \\
Union density + union coverage & 0.08 \\
Union coordination & $(1.68)$ \\
& -3.06 \\
Employer coordination & $(2.35)$ \\
Labor market expenditure & -3.95 \\
& $(3.46)$ \\
$R^{2}$ & -0.09 \\
Adjusted $R^{2}$ & $(2.14)$ \\
\end{tabular}

Source: Authors' calculations using data supplied by Richard Layard, London School of Economics, and Stephen Nickell, University of Oxford.

a. The table shows regressions of the form

$$
u_{80 \mathrm{~s}}=v_{0}+v_{1} Y+\varepsilon
$$

where $u_{80 \mathrm{~s}}$ is the average unemployment rate in the $1980 \mathrm{~s}$ and $Y$ is the set of explanatory variables. The institutional measures are averages for the nineteen countries in table 2 for the period 1983-88. $t$-statistics are in parentheses.

forces-productivity growth and the rest-we think that exclusive reliance on institutional change as an explanation of recent developments is premature.

Our approach differs from that of Elmeskov, Martin, and Scarpetta in that they examine a panel of countries in which the institutional variables explain mainly the cross-sectional variation in unemployment as in table 6 . They do not test whether changes in labor market institutions as opposed to macroeconomic variables can account for observed changes in average unemployment. To repeat, it is possible that these institutions have mainly been important in determining the impact of global shocks rather than as the forcing variables.

We now attempt to explain variation in the change in unemployment between the periods 1980-89 and 1990-98 across the nineteen OECD countries by changes in the institutional variables alone. Table 7 presents the results, which show that an increase in union coordination tends to decrease unemployment. However, this result stems only from a fall in union coordination in Finland, which experienced a rise in unemployment. 
Table 7. Regressions Explaining Changes in Unemployment, 1980s to 1990s, with Labor Market Reforms ${ }^{\mathrm{a}}$

\begin{tabular}{lc}
\hline Independent variable & Estimated coefficient \\
\hline Constant & 2.42 \\
& $(2.13)$ \\
Average unemployment rate in the 1980s & -0.20 \\
& $(1.17)$ \\
Replacement ratio & -0.20 \\
& $(1.02)$ \\
Duration of benefits & 0.61 \\
& $(0.72)$ \\
Union density & 0.13 \\
& $(1.00)$ \\
Union coordination & -5.53 \\
& $(4.17)$ \\
Employer coordination & 5.25 \\
& $(1.40)$ \\
Labor market expenditure & -0.01 \\
& $(0.07)$ \\
Union coverage & 0.76 \\
Employment protection & $(0.50)$ \\
& -0.72 \\
$R^{2}$ & $(0.42)$ \\
Adjusted $R^{2}$ & 0.73 \\
\end{tabular}

Source: Authors' calculations using data supplied by Richard Layard, London School of Economics, and Stephen Nickell, University of Oxford.

a. The table shows regressions of the form

$$
u_{90 \mathrm{~s}}-u_{80 \mathrm{~s}}=v_{0}+v_{1} u_{80 \mathrm{~s}}+\nu_{2} \Delta Y+\varepsilon
$$

where $u_{90 \mathrm{~s}}$ is the average unemployment rate in the $1990 \mathrm{~s}, u_{80 \mathrm{~s}}$ is the average rate in the $1980 \mathrm{~s}$, and $Y$ is the set of explanatory variables. Data are average values for the nineteen countries in table 2 for the periods 1983-88 and 1989-94. $t$-statistics are in parentheses.

All the other variables describing labor market reforms are insignificant, and some are incorrectly signed.

Next we test for the effect of macroeconomic shocks; table 8 reports the results. We include the change in the normalized nonwage support and the change in the rate of productivity growth while omitting the least significant among the institutional variables. An increase in the share of income from private wealth to GDP is associated with an increase in the unemployment rate, and an increase in the rate of productivity growth is associated with a fall in unemployment.

On the basis of this and other evidence, we believe that variation in macroeconomic shocks alone cannot adequately explain the variation in 
Table 8. Regressions Explaining Changes in Unemployment, 1980s to 1990s, with Macroeconomic Shocks ${ }^{\mathrm{a}}$

\begin{tabular}{lc}
\hline Independent variable & Estimated coefficient \\
\hline Constant & 1.01 \\
& $(1.04)$ \\
Average unemployment rate in the 1980s & -0.04 \\
& $(0.43)$ \\
Union density & $0.32^{* *}$ \\
& 4.14 \\
Union coordination & $-5.57^{* *}$ \\
& 5.20 \\
Nonwage support & 17.50 \\
& 1.72 \\
Trend productivity growth & $-1.20^{* *}$ \\
& 1.80 \\
$R^{2}$ & 0.74 \\
Adjusted $R^{2}$ & 0.62 \\
\hline
\end{tabular}

Source: Regression results from the equation described below.

a. The table shows regressions of the form

$$
u_{90 \mathrm{~s}}-u_{80 \mathrm{~s}}=v_{0}+v_{1} u_{80 \mathrm{~s}}+v_{2} \Delta Y+\varepsilon,
$$

where $u_{90 \mathrm{~s}}$ is the average unemployment rate in the $1990 \mathrm{~s}, u_{80 \mathrm{~s}}$ is the average rate in the $1980 \mathrm{~s}$, and $Y$ is the set of explanatory variables: nonwage support, trend productivity growth, and the fitted unemployment rate from benchmark equation 2 . $t$-statistics are in parentheses. $* *$ denotes significance at the 5 percent level.

the evolution of unemployment without taking into account differences in the way these economies respond to such shocks, including institutional differences. Our estimation results for equation 2 in tables 1 and 2 demonstrate the potency of the interplay of institutions and shocks and demonstrate that these interactive effects can explain the differences in unemployment trends across the countries.

We conclude that the institutional reforms in the OECD proposal can only be a small part of the story. In several countries, such as Ireland, equilibrium unemployment has fallen in the absence of net reform, in our estimation, whereas in others the net reform has apparently not affected equilibrium unemployment significantly.

\section{Monetary Theses}

Here we examine first the hypothesis that tight monetary policy in France, Italy, and some other aspirants to EMU membership operated to keep employment far below its structuralist equilibrium path. This could explain why unemployment was higher in 1998 than what our baseline 
equation predicted in France, Germany, Italy, and Spain. The idea is that countries that try to defend the value of their currencies by raising their interest rates suffer an additional rise in unemployment.

We again used the cross section of nineteen OECD countries to attempt to explain the variation in unemployment growth between the 1980s and 1990 s with variation in changes in different measures of monetary policy. In particular, we focused on the following hypotheses:

- That changes in the average rate of inflation may cause changes in average unemployment, as argued by George Akerlof, William Dickens, and George Perry. ${ }^{32}$ Here expected inflation enters the cognitive model used by decisionmakers only if inflation is above some threshold. The result is a permanent trade-off between inflation and unemployment at low rates of unemployment. We included in our equations both the difference in the average inflation rate between decades and its square, to account for nonlinearities.

- That positive inflation shocks reduce average unemployment through some form of hysteresis. We included both the difference in the average inflation shock between the two decades and the difference between the maximum positive and negative inflation shocks in each of the decades.

- That changes in average short-term nominal or real interest rates cause changes in average unemployment. Here we take a rise in either to represent contractionary monetary policy.

-Finally, that changes in the average slope of the yield curve from decade to decade may signify a regime shift in the monetary policy stance.

We first report, in table 9, the results for the inflation variables. Column 9-1 shows that the average level of inflation is correlated with the average level of unemployment, but the two measures of inflation shocks - which measure changes in the rate of inflation within each period-perform poorly (columns 9-2 and 9-3). An increase in average unemployment tends to accompany a decrease in the average level of inflation. This is in accordance with the thesis of Akerlof and coauthors but explains only around 15 percent of the variation in the data, indicating that this cannot be the most important causal variable. We also included a dummy variable for those countries that stayed in the European monetary system during the 1990s, but this did not affect the results reported in the table, and the dummy was insignificant in every case.

32. Akerlof, Dickens, and Perry (1996). 
Table 9. Regressions Explaining Changes in Unemployment, 1980s to 1990s, with Inflation Variables ${ }^{\mathrm{a}}$

\begin{tabular}{|c|c|c|c|c|}
\hline \multirow[b]{2}{*}{ Independent variable } & \multicolumn{4}{|c|}{ Equation } \\
\hline & $9-1$ & $9-2$ & $9-3$ & $9-4$ \\
\hline Constant & $\begin{array}{c}1.02 \\
(0.64)\end{array}$ & $\begin{array}{l}3.16^{* * *} \\
(2.27)\end{array}$ & $\begin{array}{l}-1.96 \\
(1.33)\end{array}$ & $\begin{array}{c}2.84 \\
(1.81)\end{array}$ \\
\hline Average unemployment rate in the 1980 s & $\begin{array}{c}-0.27 \\
(1.85)\end{array}$ & $\begin{array}{c}-0.19 \\
(1.07)\end{array}$ & $\begin{array}{c}-0.20 \\
(1.23)\end{array}$ & $\begin{array}{c}-0.12 \\
(0.64)\end{array}$ \\
\hline Level of inflation & $\begin{array}{l}-1.32 * * \\
(2.02)\end{array}$ & & & \\
\hline Level of inflation squared & $\begin{array}{c}-13.08 * * \\
(1.97)\end{array}$ & & & \\
\hline Average inflation shock & & $\begin{array}{c}0.08 \\
(0.67)\end{array}$ & & \\
\hline Average inflation shock squared & & $\begin{array}{c}-2.76 \\
(1.19)\end{array}$ & & \\
\hline Maximum positive inflation shock & & & $\begin{array}{c}-0.08 \\
(0.63)\end{array}$ & \\
\hline Maximum positive inflation shock squared & & & $\begin{array}{c}-1.05 \\
(0.40)\end{array}$ & \\
\hline Maximum negative inflation shock & & & & $\begin{array}{c}-0.03 \\
(1.67)\end{array}$ \\
\hline Maximum negative inflation shock squared & & & & $\begin{array}{c}-0.14 \\
(0.31)\end{array}$ \\
\hline$R^{2}$ & 0.29 & 0.15 & 0.13 & 0.18 \\
\hline Adjusted $R^{2}$ & 0.15 & -0.02 & -0.05 & 0.01 \\
\hline
\end{tabular}

Source: Regression results from the equation described below.

a. The table shows regressions of the form

$$
u_{90 \mathrm{~s}}-u_{80 \mathrm{~s}}=v_{0}+v_{1} u_{80 \mathrm{~s}}+v_{2} \Delta Y+\varepsilon,
$$

where $u_{90 \mathrm{~s}}$ is the average unemployment rate in the $1990 \mathrm{~s}, u_{80 \mathrm{~s}}$ is the average rate in the $1980 \mathrm{~s}$, and $Y$ is the set of explanatory variables: average inflation, the average of the first difference of inflation, and the difference between the largest annual changes in the inflation rate in each decade. $t$-statistics are in parentheses. $* *$ denotes significance at the 5 percent level.

We then looked at the change in average (short-term) real and nominal interest rates between the two decades and the change in the average slope of the yield curve. Of these, the real rate of interest performs best (table 10). Changes in the domestic (short-term) real rate of interest go hand in hand with changes in average unemployment. An increase in the shortterm rate, representing contractionary monetary policy, raises the average rate of unemployment, but the variable can explain only around 25 percent of the variation in the data. An upward-sloping yield curve, representing expansionary monetary policy, is also associated with high unemployment. Finally, in a regression that included both the level of inflation and the short-term real rate of interest, the latter gave better results. 
Table 10. Regressions Explaining Changes in Unemployment, 1980s to 1990s, with Interest Rate Variables

\begin{tabular}{lccc}
\hline & \multicolumn{3}{c}{ Equation } \\
\cline { 2 - 4 } Independent variable & $13-1$ & $13-2$ & $13-3$ \\
\hline Constant & 4.11 & 1.55 & 1.60 \\
& $(2.83)$ & $(1.16)$ & $(0.65)$ \\
Average unemployment rate in the 1980s & -0.24 & -0.13 & $(1.20)$ \\
Real interest rate & $(1.74)$ & $(0.91)$ & \\
Real interest rate squared & 0.84 & & \\
Nominal interest rate & $(3.16)$ & & \\
& -0.53 & & \\
Nominal interest rate squared & $(4.22)$ & -0.69 & $(0.48)$ \\
Yield curve & & -0.08 & $(0.42)$ \\
Yield curve squared & & & 0.20 \\
$R^{2}$ & & & 0.35 \\
Adjusted $R^{2}$ & & & 0.21 \\
\hline
\end{tabular}

Source: Regression results from the equations described below. a. The table shows regressions of the form

$$
u_{90 \mathrm{~s}}-u_{80 \mathrm{~s}}=v_{0}+v_{1} u_{80 \mathrm{~s}}+v_{2} \Delta Y+\varepsilon
$$

where $u_{90 \mathrm{~s}}$ is the average unemployment rate in the $1990 \mathrm{~s}, u_{80 \mathrm{~s}}$ is the average rate in the $1980 \mathrm{~s}$, and $Y$ is the set of explanatory variables: the average of the short-term real rate of interest (one-year government bonds), the average of the short-term nominal interest rate, and the average slope of the yield curve (long minus short). $t$-statistics are in parentheses.

These results constitute some evidence that differences in monetary policy across countries made a difference for their unemployment experience over the course of the decade. It remains a tenable hypothesis that monetary policy in Continental Europe caused unemployment to exceed its natural path over most of the 1990s, for reasons having to do with the runup to EMU, the Maastricht Treaty, and the tight-money policies instituted by the Deutsche Bundesbank to offset expenditure for German unification. But the evidence is not conclusive. Moreover, the tight-money episode, however important its influence may have been, appears to be over. Germany and most of the economies tied closely to it, such as Belgium, France, Italy, and Spain, no longer have comparatively high shortterm real rates of interest; rates in Finland, Ireland, the Netherlands, Portugal, and the United Kingdom are appreciably higher, some markedly 
so. ${ }^{33}$ Correspondingly, in the first group of countries the unemployment rate has tended to recede, mostly in 1998-99, to levels of the early 1990s. In France, for example, unemployment has fallen to 10.6 percent, a level last seen in 1992. And inflation rates have stopped falling. So it is doubtful that monetary policy over the whole decade is still playing a part in the failure of employment in these countries to recover more strongly.

To sum up the results thus far: in our analysis, cross-country variation among OECD countries in the pace of labor market reform and in changes in inflation and nominal interest rates do not adequately account for the observed variation in the fall in unemployment. To explain the variation in the unemployment data found in the 1990s - to understand why unemployment has, for example, fallen so much in Ireland and the United States while remaining so high in France and Italy - therefore requires adding at least one other causal force to the account. We turn now to our own proposed hypothesis.

\section{The Role of Asset Prices in the Employment Impact of the "New Economy"}

We begin by arguing that the prospect of a "new economy"- a prospect closer at hand in some OECD countries than in others-offers in theory a possible explanation of the uneven structural recoveries of the 1990s. We then assess the predictions of this argument against a variety of evidence.

The thesis goes roughly as follows. In virtually every OECD country, recent advances in information and communications technologies have created expectations of a large stepup in productivity, and thus in the profit per unit on various business assets. The prospect of a world in which most firms and persons can access the Internet from computers, mobile phones, and television has stimulated expectations of new opportunities for profitable investment, including investment in new employees, although these opportunities are seen as more imminent in some countries than in others. Where this prospect appears to be relatively near, as in the United States, there has been a galvanizing effect among telecommunications firms and among equipment manufacturers, service providers, and content produc-

33. See the convenient table in Financial Times, June 12, 1999. 
ers for the Internet. The consequent rise in financial wealth in this sector has had the secondary effect of driving up home construction and other investment in consumer durables. As a result, the economy appears to have all the trappings of a general investment boom. We would note that the expectation of any other development boosting expected profitability at some time in the future-globalization or advances in biogenetics, for example - would serve as well. (Of course, to the extent the expectation comes to be seen as exaggerated and is therefore revised downward, the boom will be scaled back. But it is the expectation that matters, as long as it lasts.)

This confidence-driven investment boom, our thesis continues, has the effect of creating jobs and pulling up real wages. And the mechanism that ties the expected future leap of profitability to a boom in the labor market involves changes in the valuation of business assets. The transmission of the boom from business asset markets to the labor market is tailor-made for our forward-looking structuralist model—not that our models are likely to be the only ones to portray expectations of a new earnings plateau in the future as sparking an inflation-free boom in the present. Although employee incentives are the heart of these incentive wage models' generation of unemployment (without them there would be no unemployment), our models also have a brain. Value-maximizing firms form expectations about the gross profit stream obtainable over the future from new investments, which drives real valuations of business assets, which in turn have an impact on rates of investment in these assets and ultimately on the equilibrium (that is, correct-expectations) path of employment. In these models, an anticipated one-time step increase in productivity precipitates an immediate jump of asset values in anticipation of greater returns (rents) on those assets once productivity has increased, and such revaluations lead immediately to rising employment in the near term as well as a rise in real wages. Obviously the value that managers rationally place on an employee having the requisite familiarization with and orientation to the firm's operations and objectives (firm-specific training) is one of these revaluations, and an important one. However, the argument does not absolutely require the assumption of firm-specific training, since the other asset revaluations may very well affect positively the demand for labor.

A stylized description of the effects of the future productivity shock under discussion is provided by the turnover-training model, which focuses exclusively on the intellectual capital that firms invest in their work forces and supposes for simplicity that all firms in the model's open 
economy are in the same industry. Figure 4 describes how the expectation of a single future step increase in the marginal and average value productivity of employees causes an anticipatory jump in the valuation of the trained employee. Importantly, employment is related here to the asset price normalized by productivity. ${ }^{34}$ The reason is that hiring depends on the ratio of the asset price, $q^{N}$, to productivity, $\Lambda \varphi$; so, indirectly, does quitting. ${ }^{35}$ In figure 4 , the asset price curve depicts how, if it were stationary, the ratio of the asset price to productivity $\left(q^{N} / \Lambda \varphi\right)$ would depend on the tightness of the labor market $(1-u)$, and the employment curve depicts how, if it were stationary, the level of $1-u$ would depend on $q^{N} / \Lambda \varphi$. The medium-term rest point is at the curves' intersection. ${ }^{36}$

With this diagram we can describe precisely the equilibrium scenario that follows the newfound expectation of a future increase in productivity. Starting from the rest point, $q^{N} / \Lambda \varphi$ must jump upward in anticipation of the increased $q^{N}$ following the future increase in productivity. Thereupon, both $q^{N} / \Lambda \varphi$ and $1-u$ must be rising, as hiring is up and quitting is down, owing to the rise of $q^{N}$ relative to $\Lambda \varphi$, although the ensuing labor market tightening will operate to attenuate those two effects. When the great day arrives, $q^{N} / \Lambda \varphi$ must jump downward, since $\Lambda$ jumps upward and $q^{N}$ does not jump at all. Thereafter $q^{N}$ continues to rise, gradually regaining its former proportionality with $\Lambda$. In this aftermath, employment recedes back to its steady-state level, since $q^{N}$ in this phase is depressed relative to productivity. ${ }^{37}$ It is important to add that the positive impact of

34. The valuation of a prepared employee is normalized by the productivity of workers on the production line gross of the interest and depreciation on the equipment used, since employees moving from production to training are assumed to need an unchanged assortment of equipment.

35. Given nonwage income relative to productivity, quitting is a function of the wage relative to productivity, which wage setting makes a function of asset valuation relative to productivity.

36. Appendix $\mathrm{C}$ provides information on the structure of the model, the slopes of the two curves, and the dynamics of the system. Or see Hoon and Phelps $(1992,1996)$ and Phelps (1994).

37. Another sort of shock is the sudden increase in the expected and actual growth rate of productivity. We do not rely on this kind of shock to motivate the introduction of asset prices, since if it were the only kind occurring, we would expect that our measured productivity growth variable would suffice to pick up the workings of this expectation. For the record, such a shock shifts the asset price curve upward. Thus it lifts the downward-sloping equilibrium approach path governing employment and the normalized asset value. In the equilibrium scenario, starting from the rest point, $q^{N} / \Lambda \varphi$ overshoots, subsequently giving up some of its gain along the path to the rest point. 
Figure 4. Response of Employee Valuation to an Expected Increase in Employee Productivity

Asset prices normalized to productivity $\left(q^{N} / \Lambda \varphi\right)$

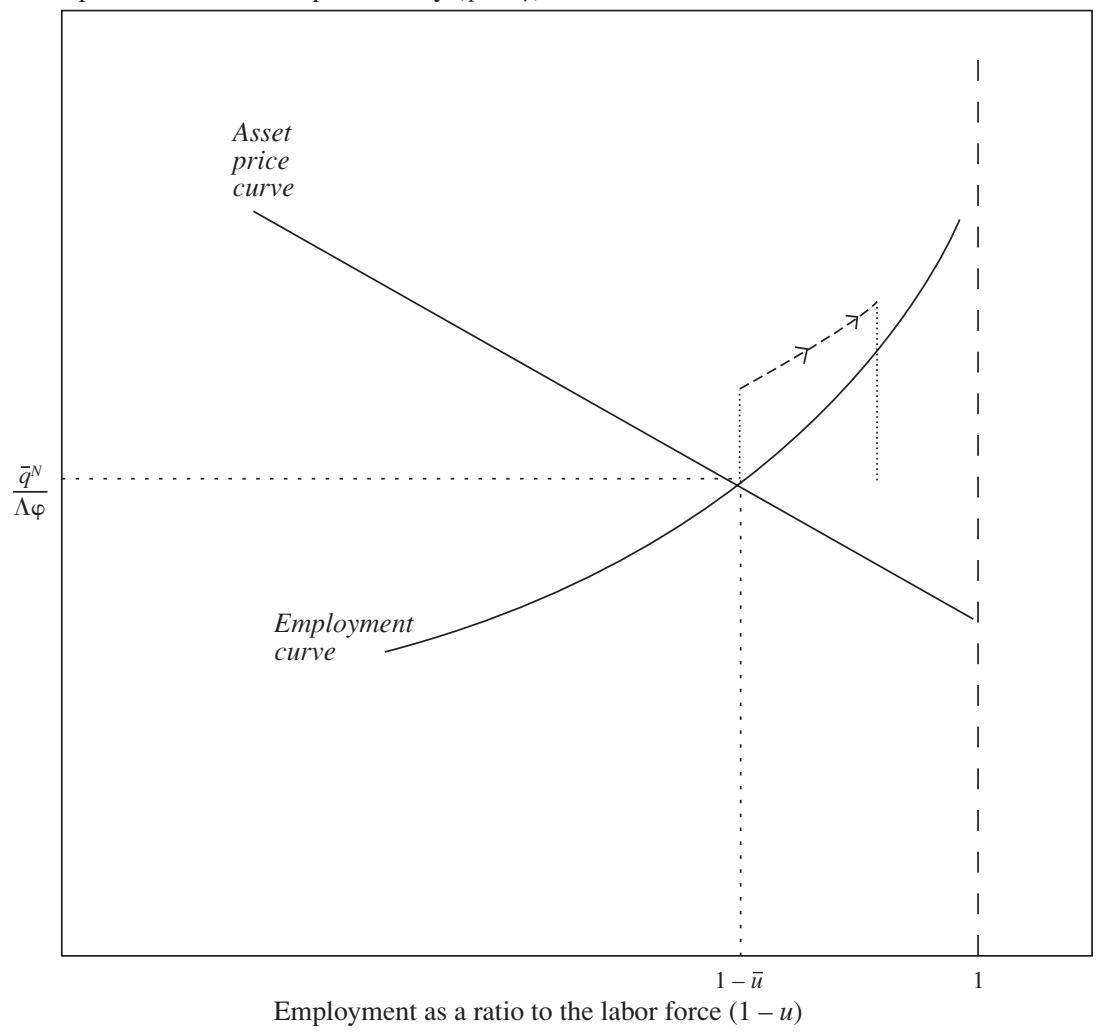

expected future profitability on the valuation of (nontradable) capital goods, such as office and factory space, is also expansionary. ${ }^{38}$

An ideal test of these structuralist models would estimate what impact the valuations placed by managers on trained employees, tangible capital goods, and customers have on the pace of employment increase. Lacking

38. Suppose that this good is produced with labor alone, but that the sector producing consumer goods uses the nontradable capital good as well as labor. Then the increase in the price of the capital good is a rise in the value productivity of labor producing it. As a result, wage rates are initially pulled upward relative to wealth, quit rates drop, and both the asset price curve and the employment curve are shifted in an expansionary way. 
data on most of these shadow prices, we improvise by hypothesizing that one or another measure of the firms' value in the capital market can serve as a proxy for these shadow prices. The next few sections pursue successive implementations of this idea.

Returning to our two baseline equations 1 and 2, we now proceed to explore the explanatory power of capital market measures of market capitalization either as a reflection or as a sort of cause of managers' valuations of their business assets (employees, customers, and fixed assets). In our interpretation, managers learn things that inspire them to raise their valuations, and then lay plans to invest in new (as well as old) employees. But meanwhile market analysts catch wind of the brightened prospects and drive up share prices in advance of all or most of the increase in business assets acquired. Our econometric tests are shaped accordingly. But it could be that assets do not lag behind valuations, and it is even possible that share prices lag the accumulation of business assets, both driven by brighter prospects of profitability down the road.

To begin, we try adding to the above set of explanatory variables the real share price, $p^{S}$, as a proxy for both the effective cost of capital and the profitability of one employee with his or her equilibrium outfit of tangible capital and customers. More precisely, $p^{S}$ stands as a proxy for $q^{N}$, the valuation of the trained employee. On that interpretation, the share price must be entered as a ratio to the productivity of labor, which, abstracting from capital other than trained employees for the moment, is given simply by the (advancing) technology parameter $\Lambda_{t}$. The reason is that the hiring decision must weigh the value of a new trained employee against the opportunity cost of the "trainers" orienting the new recruit. That cost is the existing employees' productivity in production. Recall, however, that although the hire rate may be simply determined in this way, the increase in employment is equal to hiring net of quitting and dismissals for shirking. In addition, the rates of quitting and of shirking are functions of the income from private and social assets that workers can fall back on when they quit or are dismissed. The new equation is:

$$
\begin{aligned}
u_{i t}= & \alpha_{i}+\mu_{i} u_{i t-1} \\
& +\theta_{i}\left(\phi^{1} r_{t-1}^{*}+\phi^{2} g_{i t-1}+\phi^{3} p_{t-1}^{*}+\phi^{4}\left(\tilde{y}_{i t-1}^{W}+\tilde{y}_{i t-1}^{S}\right) \frac{1+\tau_{i t-1}^{D}}{1-\tau_{i t-1}^{P}}+\phi^{5} \tilde{p}_{i t-1}^{S}\right) \\
& +\gamma_{i} \Delta \pi_{i t}+\varepsilon_{i t} .
\end{aligned}
$$


Note that the cost of capital, $r^{*}-g_{i}$, reappears in the equation in spite of the introduction of the stock market variable. That is because the former has an impact on the amount of interest to be deducted from productivity in the calculation of the "demand wage" from the condition of zero pure profit (even if the valuation of the asset were unchanged). And a decrease in the demand wage, by stimulating more quitting, lowers employment growth at the current unemployment rate. ${ }^{39}$ We stress that if the cost of capital receives credit for its total effect on employment in the statistical estimation, the share price will play the role of conveying expectations of future shocks to productivity and thus profitability.

Table 11 presents the results. When the normalized share price is included, in column 11-2, we find it to have a negative coefficient-a higher value corresponds to lower unemployment—and it is significant at the 5 percent level.

Column 11-3 instead adds the ratio of the national share price index to the OECD average share price in the sample, to test whether domestic share prices survive as a significant explanatory variable when the world average is introduced. We find that they do. It is of interest to note that, since the coefficients on the two stock market indicators are not significantly different from each other, an increase in the world share price index that is unaccompanied by a change in the national share price index has no significant effect on that nation's own unemployment rate.

A basic question posed by this paper is whether differences in the evolution of share prices across countries can explain why some economies' employment rates have improved more than expected, while others have done worse..$^{40}$ We now look at the country data to see whether we can explain the pattern shown in table 5-that is, to see why some countries have had lower and others higher unemployment in the recent past than predicted by our baseline equation. We rank the countries according to the rise in average share prices and the change in average unemployment

39. There are also some by-products of the coexistence of $r^{*}-g_{i}$. with the share price. There is a benefit from having the cost of capital there, if our data on average share price are not accurate depictors of the value of the business sector as a whole, or if share price fluctuations are neither the effect nor the cause of changes in managers' valuations of business assets. Then it is at least possible that $r^{*}$ and $g$ will survive to demonstrate that asset valuations are important.

40. A related question is whether, at the microeconomic level, company employment moves with share prices in the long run-that is, do persistently low share prices imply persistently low employment? Appendix D finds that this is in fact so in our sample. 
Table 11. Baseline Equation Explaining Unemployment with Measures of Share Prices Added, 1960-98 ${ }^{\text {a }}$

\begin{tabular}{|c|c|c|c|}
\hline \multirow[b]{2}{*}{ Independent variable } & \multicolumn{3}{|c|}{ Equation } \\
\hline & $11-1$ & $11-2$ & $11-3$ \\
\hline World real rate of interest & $\begin{array}{l}0.01 * * \\
(2.10)\end{array}$ & $\begin{array}{l}0.02 * * \\
(2.18)\end{array}$ & $\begin{array}{l}0.01 * * \\
(2.11)\end{array}$ \\
\hline Trend productivity growth & $\begin{array}{l}-0.04 * * \\
(2.16)\end{array}$ & $\begin{array}{c}-0.02 \\
(0.93)\end{array}$ & $\begin{array}{c}-0.02 \\
(1.25)\end{array}$ \\
\hline Real price of oil & $\begin{array}{l}0.80 * * \\
(3.45)\end{array}$ & $\begin{array}{l}0.48 * * \\
(2.58)\end{array}$ & $\begin{array}{l}0.41^{* *} \\
(2.42)\end{array}$ \\
\hline Nonwage support & $\begin{array}{l}2.44 * * \\
(2.95)\end{array}$ & $\begin{array}{l}2.39 * * \\
(2.52)\end{array}$ & $\begin{array}{l}2.31 * * \\
(2.59)\end{array}$ \\
\hline Share price normalized by productivity & & $\begin{array}{l}-0.26^{* * *} \\
(2.48)\end{array}$ & \\
\hline Relative share price & & & $\begin{array}{c}-0.18^{* *} \\
(2.55)\end{array}$ \\
\hline World average share price & & & $\begin{array}{c}-0.29 * * \\
(2.28)\end{array}$ \\
\hline
\end{tabular}

between the 1970s (1970-79) and the 1990s (1990-99) and show the relationship between the two in figure 5 . The rank correlation is -0.60 , which implies that the greater the rise in share prices, the smaller the rise (or the larger the fall) in average unemployment.

This relationship also emerges when we add the change in the normalized share price between the average of the 1980s and the average of the 1990s to the cross-section estimation above. Table 12 is an extension of table 8 in that changes in share prices are added to the list of macroeconomic shocks.

We now look more closely at U.S. data; then at data from the highunemployment countries of France, Germany, Italy, and Spain; and finally at data from two countries that have had lower unemployment than expected: Ireland and New Zealand.

\section{United States}

In the United States, estimates of the natural rate of unemployment drifted upward in the 1970s and 1980s, ${ }^{41}$ but data for the 1990s show a

41. See Juhn, Murphy, and Topel (1991) and Phelps and Zoega (1997). 
Figure 5. Ranking of Eighteen OECD Countries by Changes in Share Prices and in Unemployment Between 1970-79 and 1990-99

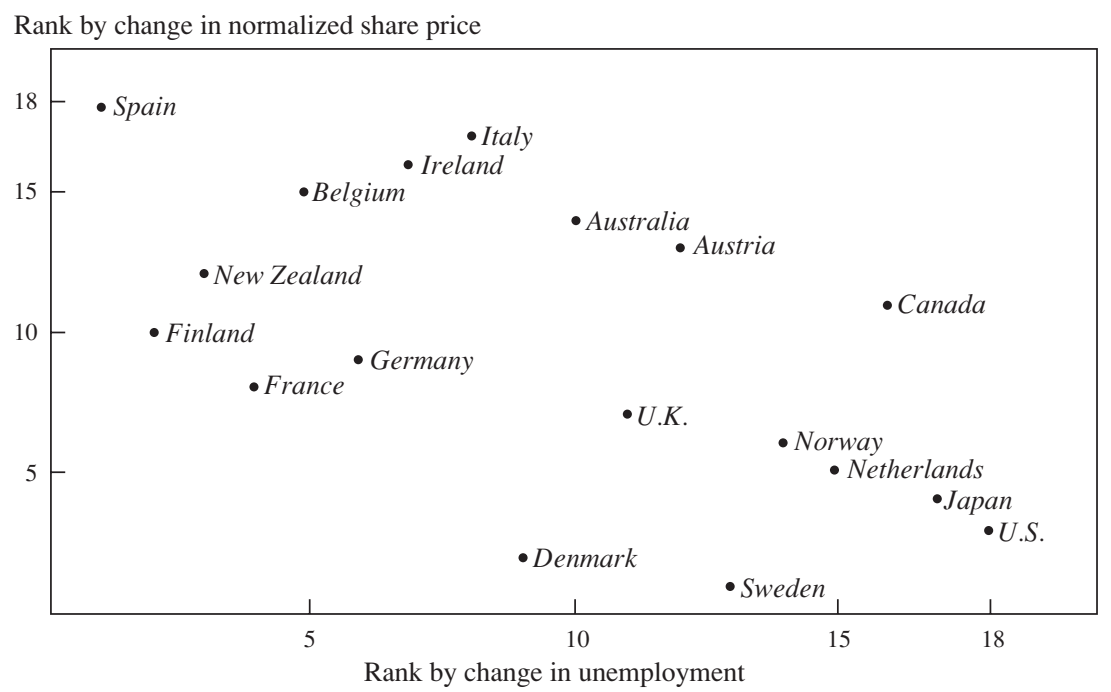

Source: IMF, International Financial Statistics, various issues; OECD Employment Outlook, various issues.

a. The country with the largest rise in normalized share prices (or in unemployment) is ranked 1 , and the country with the smallest rise (or largest fall) is ranked 18. (Portugal is excluded because of lack of data.) Share prices are normalized to productivity.

downward movement, with a sharp drop beginning at mid-decade. The U.S. unemployment rate in 1998 was around 1.56 percentage points below what our baseline regression predicted in out-of-sample simulations. The forces behind these recent developments are a subject of debate. One of us recently argued that the steep descent of the natural rate in the United States since early 1995 is closely associated with the stock market boom: ${ }^{42}$ The rise in the price of equity may reflect a rise in the valuation of the marginal employee. That in turn would cause the rate of inflow into employment to increase, as firms expand their hiring and training. To assess this hypothesis, we show in figure 6 a stock market index for the United States, normalized by productivity, alongside the rate of employment.

It appears that the share price series tracks the low-frequency, decadeto-decade movements in the employment rate fairly well. Note that this occurs at lower than so-called business-cycle frequencies. In fact, the dis-

42. Phelps (1999). 
Table 12. Regressions Explaining Changes in Unemployment, 1980s and 1990s, with Macroeconomic Shocks Including Share Prices ${ }^{a}$

\begin{tabular}{lc}
\hline Independent variable & $\begin{array}{c}\text { Estimated } \\
\text { coefficient }\end{array}$ \\
\hline Constant & $2.33^{* *}$ \\
& $(2.29)$ \\
Average unemployment rate in the 1980s & -0.01 \\
& $(0.09)$ \\
Union density & 0.29 \\
& $(0.86)$ \\
Union coordination & $-3.97^{* *}$ \\
Nonwage support & $(2.46)$ \\
& $33.58^{* *}$ \\
Trend productivity growth & $(2.08)$ \\
& -0.37 \\
Share price normalized by productivity & $(0.40)$ \\
& $-4.64^{* *}$ \\
$R^{2}$ & $(2.22)$ \\
Adjusted $R^{2}$ & 0.75 \\
\end{tabular}

Source: Regression results from the equation described below.

a. The table shows regressions of the form

$$
u_{90 \mathrm{~s}}-u_{80 \mathrm{~s}}=v_{0}+v_{1} u_{80 \mathrm{~s}}+v_{2} \Delta Y+\varepsilon,
$$

where $u_{90 \mathrm{~s}}$ is the average unemployment rate in the $1990 \mathrm{~s}, u_{80 \mathrm{~s}}$ is the average rate in the $1980 \mathrm{~s}$, and $Y$ is the set of explanatory variables. $t$-statistics are in parentheses. $* *$ denotes significance at the 5 percent level.

crepancy between the two series points to business cycles that have brought either accelerating or decelerating inflation. This indicates a divergence between the actual unemployment rate and the natural rate. Data for the late 1960s, a period of rising inflation, show a rise in employment not explained by high asset prices. The early 1980s witnessed a cyclical downturn caused by the disinflation engineered by the Federal Reserve under Paul Volcker. Finally, and perhaps most interestingly, in the last few years unemployment may have been above its natural rate, not because of a rise in actual employment but because of a fall in the natural rate itself. This may have allowed the unparalleled recent expansion to continue without rising inflation.

\section{France, Germany, Italy, and Spain}

These four countries all had higher unemployment in the 1990s than expected from our baseline equation 2. Figure 7 shows the normalized share price index and the employment rate for these countries. 
Figure 6. Normalized Share Prices and the Employment Rate in the United States, 1960-99

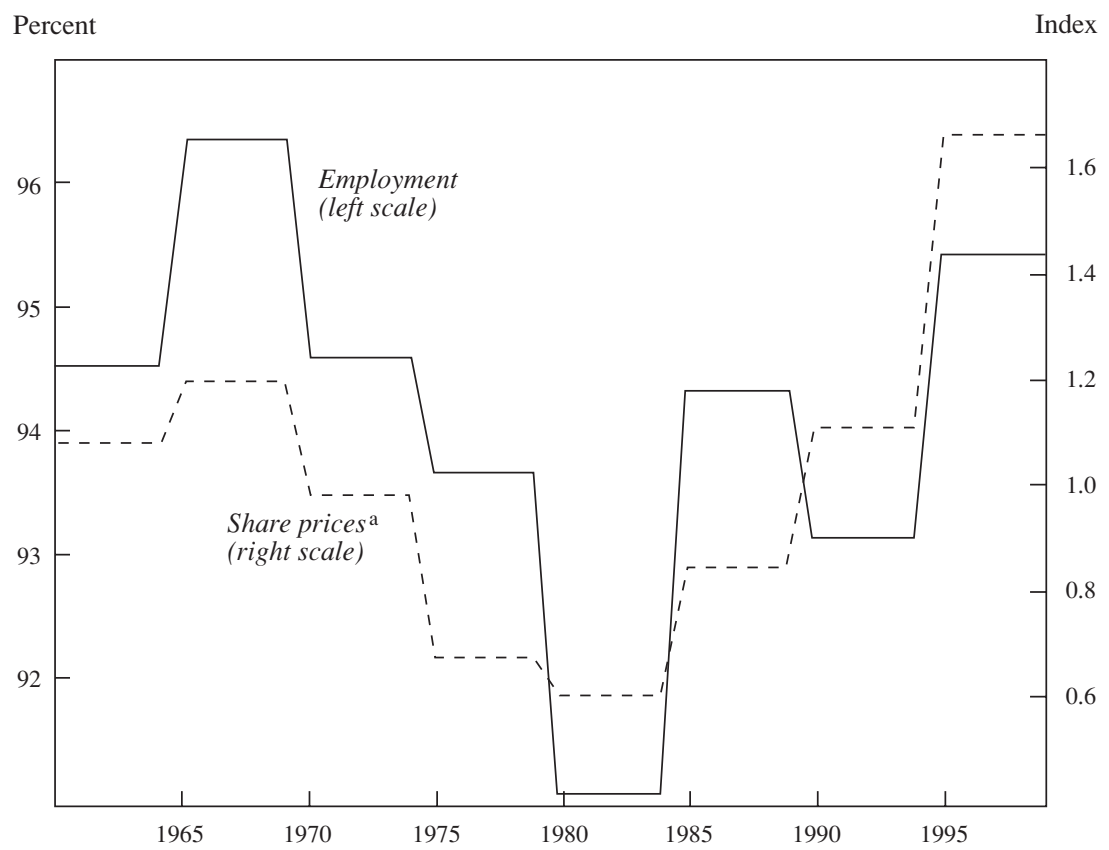

Source: Interational Monetary Fund, International Financial Statistics, various issues; OECD Employment Outlook, various issues.

a. Share prices are normalized to productivity.

In Spain the relationship is very clear. The fall in employment that started around 1975 was preceded by a fall in real share prices. The persistently low rate of employment after 1980 also corresponds to persistently low real share prices.

In France the employment rate started its descent around the same time as in Spain, although a slight fall can be seen as early as the late 1960s. A fall in share prices preceded the drop in employment to a lower plateau. However, an important difference with Spain has arisen in recent years. Since 1985 the French stock market has recovered much of its lost ground. Its value in 1998 was not much different from that found in the early 1970s when the data are normalized by productivity. But the employment rate has not recovered significantly. This implies either that the stock market was overvalued in the 1990s or that the country is in a disequilibrium slump, with the rate of unemployment exceeding the natural rate. 
Figure 7. Normalized Share Prices and Employment Rates in France, Germany, Italy, and Spain, 1960-99
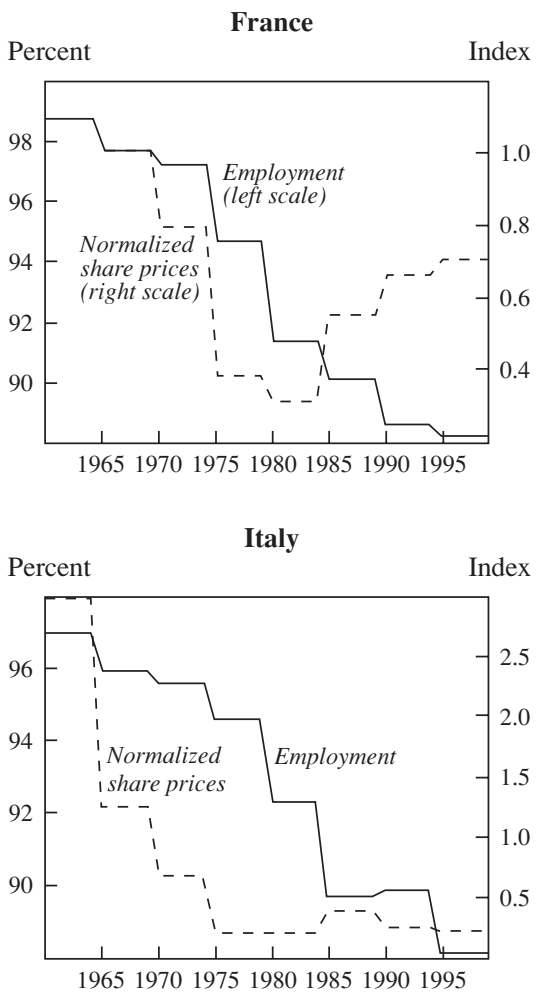

Germany

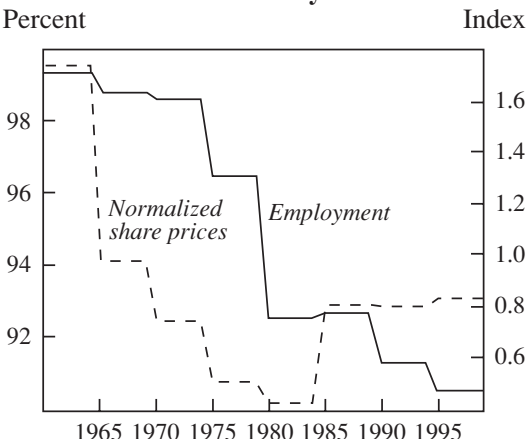

Spain

Percent Index

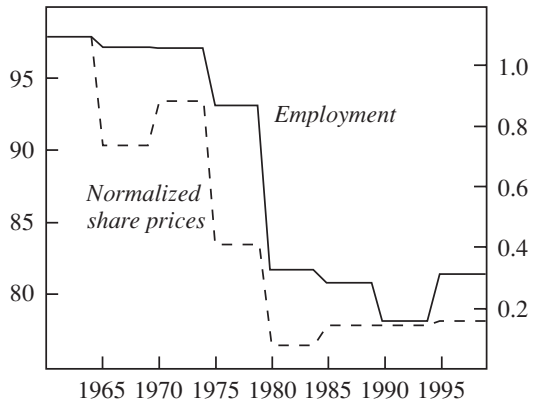

Source: International Monetary Fund, International Financial Statistics, various issues; OECD Employment Outlook, various issues.

a. Share prices are normalized to productivity.

German employment started its descent slightly later. It fell sharply in the first halves of the 1970s and the 1980s and then again in the 1990s. This fall was preceded by falling share prices. As in France, however, the further fall in the 1990s is not explained by a further fall in share prices. Share prices recovered some of their lost ground in the latter part of the 1980s, as did employment, but then held their ground through the 1990s, when employment declined somewhat.

Italy shares the time pattern of France and Germany to a large extent. Both real share prices (again normalized by productivity) and the rate of employment were on a downward trend from the mid-1960s up to 1980. The continued rise in unemployment after 1980 can be interpreted as, ini- 
tially, a delayed response to the earlier fall in asset valuations reflected in stock market prices, and then, in the 1990s, as a result of the restrictive monetary policy that preceded the establishment of the single currency.

\section{Ireland, the Netherlands, and New Zealand}

Finally, we show in figure 8 three of the recent good performers among the OECD's success stories: Ireland, the Netherlands, and New Zealand have all had rising employment in the past five years or so. Share prices rose prior to the recent rise in employment. Although this is in no way conclusive evidence for our thesis, it is a much-overlooked fact that supports our hypothesis about the role of asset prices in employment determination.

\section{Granger Causality Tests}

The long-run relationship between share prices and the rate of employment is consistent with our model. Of course, many other models would find stock price variations to be positively related to measures of economic expansion such as changes in employment. One departure of our model from the main alternatives - such as variants of the Keynesian modelinvolves the treatment of labor as a quasi-fixed asset. In our model, firms step up hiring when they become more optimistic about future profitability, even when they do not want to step up their current output and must decrease it to train more workers. In models where labor can be hired and fired at little cost, changes in employment coincide with changes in output. Another difference is that, in Keynesian models with a fixed natural rate of unemployment or a fixed Phillips curve, changes in employment should be positively correlated with inflation, and, in principle, inflation changes or levels would explain the movements in employment.

We first test explicitly whether changes in share prices precede changes in the unemployment rate. For this we perform a Granger causality test on the raw unemployment and share price series. Table 13 presents the results. The results using the raw series indicate that increases in share prices do cause decreases in the unemployment rate in all the countries, although the level of significance is low for France.

The results so far are consistent both with models that treat labor as a fixed asset and with those that do not. Therefore the next step is to regress changes in unemployment on changes in output (to take out the contemporaneous effect of expanded capacity utilization on employment) and 
Figure 8. Normalized Share Prices and Employment Rate in Ireland, the Netherlands, and New Zealand, 1960-99a
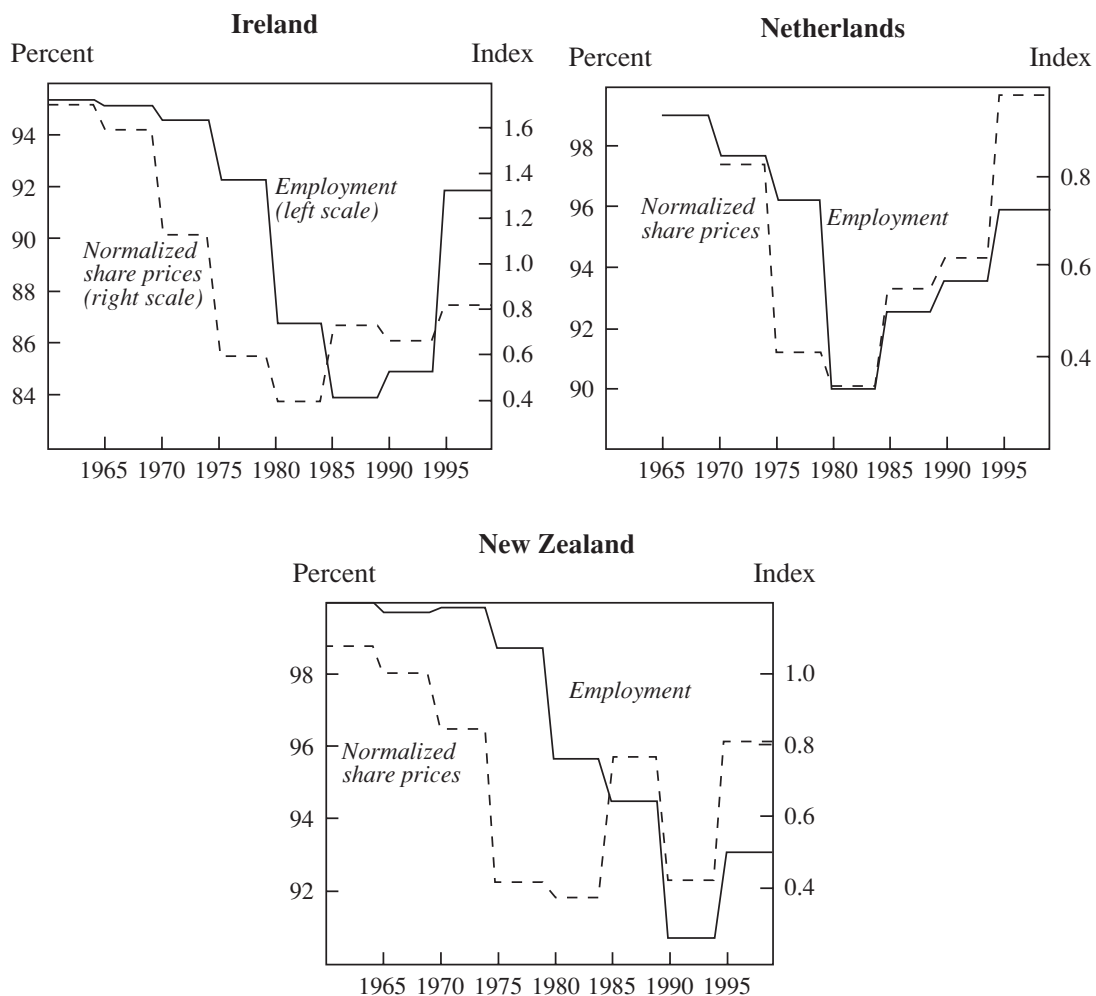

Source: International Monetary Fund, International Financial Statistics, various issues; OECD Employment Outlook, various issues.

a. Share prices are normalized to productivity.

then to take the residual change in unemployment (the corrected unemployment series in table 13) and test whether this is preceded by changes in real share prices. The last two columns of table 13 report results for this corrected unemployment series. These are consistent with the earlier results. Thus the relationship between increases in share prices and decreases in unemployment remains qualitatively unchanged by this correction for the business cycle.

On the basis of this evidence we conclude that firms increase their hiring of new workers when real share prices rise, reflecting enhanced optimism about future profitability, and that this is independent of current 
Table 13. Granger Causality Tests of Changes in Share Prices and Changes in Unemployment $^{\mathrm{a}}$

\begin{tabular}{lcccccc}
\hline & & \multicolumn{2}{c}{ Raw series } & & \multicolumn{2}{c}{$\begin{array}{c}\text { Corrected } \\
\text { unemployment }\end{array}$} \\
\cline { 7 - 8 } Country & $\begin{array}{c}\text { No. of } \\
\text { observations }\end{array}$ & $F$ & Probability & & $F$ & Probability \\
\hline France & 36 & 1.47 & 0.23 & & 2.22 & 0.15 \\
Germany & 36 & $3.93^{*}$ & 0.06 & & 1.73 & 0.20 \\
Ireland & 36 & $11.88^{* *}$ & 0.00 & & $9.17^{*}$ & 0.00 \\
Italy & 36 & $3.46^{*}$ & 0.07 & & $2.83^{*}$ & 0.10 \\
Netherlands & 36 & $10.52^{* *}$ & 0.00 & & $9.00^{* *}$ & 0.01 \\
New Zealand & 32 & $5.87^{* *}$ & 0.02 & & $6.78^{*}$ & 0.01 \\
Spain & 36 & $3.43^{*}$ & 0.07 & & 2.27 & 0.14 \\
United States & 36 & $14.12^{* *}$ & 0.00 & & $9.79^{*}$ & 0.00 \\
\hline
\end{tabular}

Source: Authors' calculations using OECD data for 1960-98.

a. The null hypothesis is that changes in real share prices do not cause changes in unemployment in the following quarter. The "Raw series" columns report a test using the raw unemployment series. The "Corrected unemployment" columns report a test using residuals from a regression of the first difference of unemployment on changes in the logarithm of real GDP. * indicates rejection of the null hypothesis at the 10 percent level, and ** rejection at the 5 percent level.

output changes. In other words, the hiring of new workers involves an investment dimension.

Since investment in physical capital may also be a function of shadow prices (that is, Tobin's $Q$, which is a ratio of $q^{k}$ to replacement cost), it is instructive to take a brief glance at the relationship between unemployment and physical investment at frequencies lower than that of the business cycle. We should note that Tobin's theory has fallen into some disrepute due to its apparent empirical failures. However, with our own forwardlooking model of investment in new workers, it is tempting to compare the predictions of the two models. Figure A5 in appendix A juxtaposes the rate of investment per unit capital and the employment rate for the G-7 countries except Japan. Although the high-frequency correlations come as no surprise, there is also a decade-to-decade correlation in France, Italy, and Germany: low-employment epochs tend also to be epochs of low investment rates. This finding is not to be expected from conventional theory. Moreover, the turning points in the unemployment series often correspond to the turning points in the rate of investment. Note that although the rise of unemployment to a higher plateau in the three unemployment-prone countries in the figure corresponds to a fall in the rate of investment to a lower plateau, both unemployment and the investment rate show no such behavior in the United States or the United Kingdom. These lowfrequency correlations can be taken as providing some empirical support for Tobin's theory or our theory or both. 


\section{Conclusions}

Our perspective on the natural rate of unemployment in any market economy is that, to begin with, it shifts. It shifts with the economy's demographics, of course, and with the economy's institutions: tax and regulatory law, corporate ownership and governance, and welfare state protections and provisions. But the natural rate does not just shift. Rather, it fluctuates as a result of business shocks that disturb firms' asset valuations, productivity, and wealth. An advantage of our models is that entrepreneurs' expectations about the future - say, future productivity, and hence future profits or future interest rates - enter the story through their impact on the valuations of the types of business assets in which firms invest, and these valuations in turn disturb product and labor markets. In our past empirical work we estimated that several market variables had unequal unemployment effects among the countries, and we sought to trace these disparities to institutional differences.

The unusual record of the 1990s permits us to go a great deal further in testing this framework. The impetus for the tests performed here is a three-part hypothesis. First, managers' asset valuations have a sufficiently strong impact on the structural equilibrium unemployment path that the two wide swings in economic activity observed in recent decades-the gathering slump that began in the mid-1970s and the powerful recovery seen in several economies in the 1990s-may very well be the effect of swings in those managerial valuations. Second, the decline and rise in market capitalizations of firms may be a serviceable mirror, even if only in a distorted or exaggerated way, of the asset valuations made by firms' managers. ${ }^{43}$ Third, the 1990 s rise in managerial valuations and the accompanying rise in the stock market went far beyond what can be explained by the capital market and other macroeconomic influences contained in our empirical work, such as world real interest rates and domestic productivity growth rates. Thus, in this instance (and possibly others), the rise in the stock market may have considerable information value when added to the set of macroeconomic explanatory factors in the study of employment. It may be a sign of managers' expectations of a one-time future lift in the path of productivity, and hence of profits, that is distinct from and

43. The first of these statements is a substantive thesis in Phelps (1994), and the second is the hypothesis explored in Phelps (1999). 
additive to any perceived improvement in the trend growth rate of productivity.

This paper begins our testing of this hypothesis. We first showed that an out-of-sample simulation of the 1990s with a stripped-down version of our previous unemployment equations provides some explanation of the recoveries, where they occurred, since many of them coincided with a quickening of domestic productivity growth, and there has been some decline in our world real interest rate series. Yet this simulation cannot fully explain the degree of recovery observed in the more successful economies of the past decade. We then showed that the labor market reforms advocated by the OECD Secretariat, although helpful in some cases, leave us far short of explaining why the countries that recovered in the 1990s did so, and by the amounts that they did. Yet, snatching victory from the jaws of defeat, we went on to show that the supplementary use of a stock market indicator in our unemployment equations aids enormously in accounting for the $1990 \mathrm{~s}$ recoveries.

This finding, we think, testifies to the importance of asset valuations in the structuralist theory of employment-no matter whether stock market prices are the prime mover driving firms to act, as hinted by Keynes and argued by Tobin, or whether, as we are inclined to suppose, these prices are more the effect of managers' valuations of business assets, based on their expectations of future profits and capital costs, than an influence on their valuations. If our results are correct, the widespread impression that stock markets have no explanatory value is mistaken. The forward-looking Fisher-Tobin treatment of investing, whether in fixed capital or in employees and customers, pays off when embedded in an essentially nonmonetary theory of employment and asset acquisition. Also striking is that the emphasis on business confidence by such early students of business fluctuations as Spiethof - the idea that beliefs about the future drive the economy through systems that need not be monetary-which had been lost for a century, may now be on its way back. 


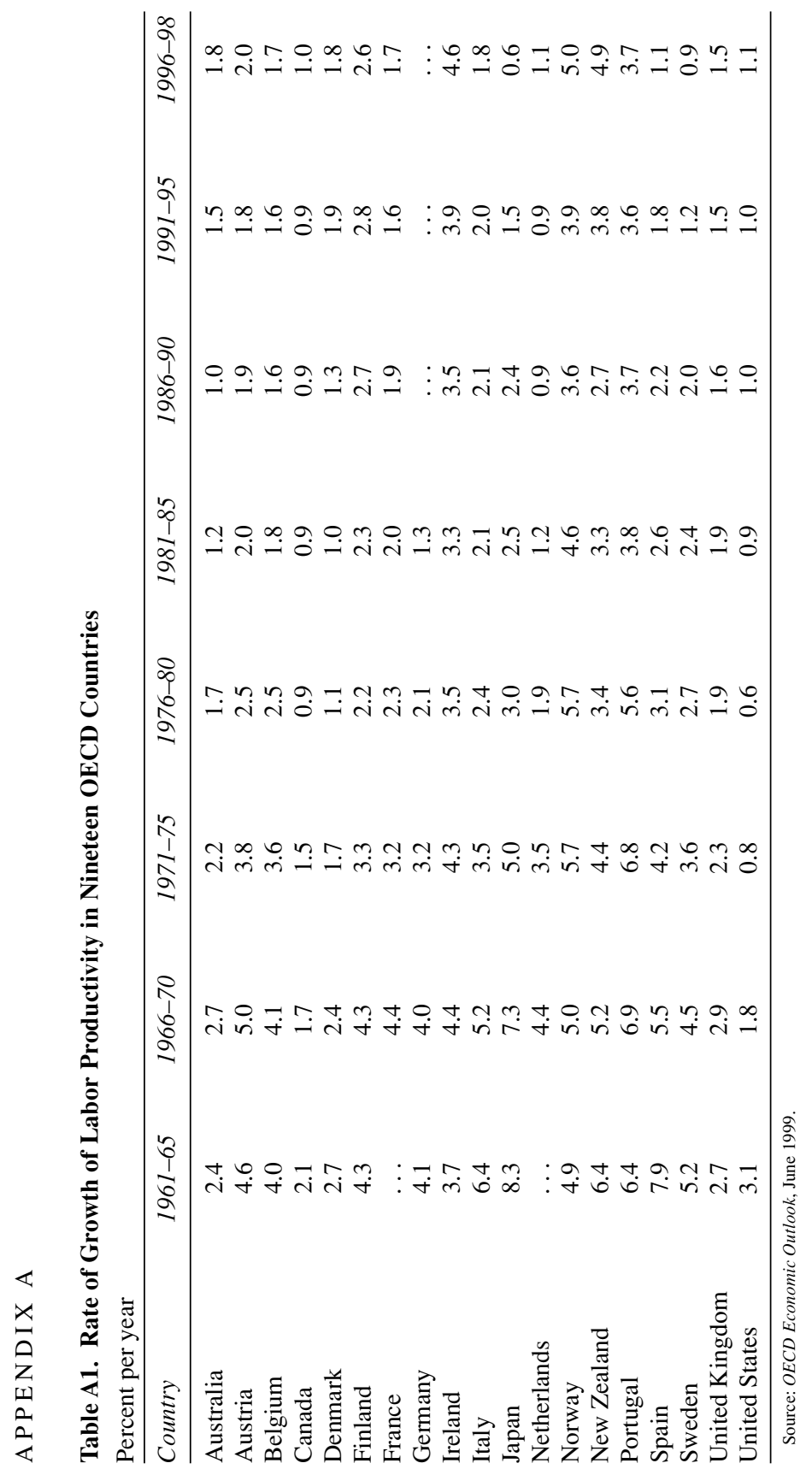




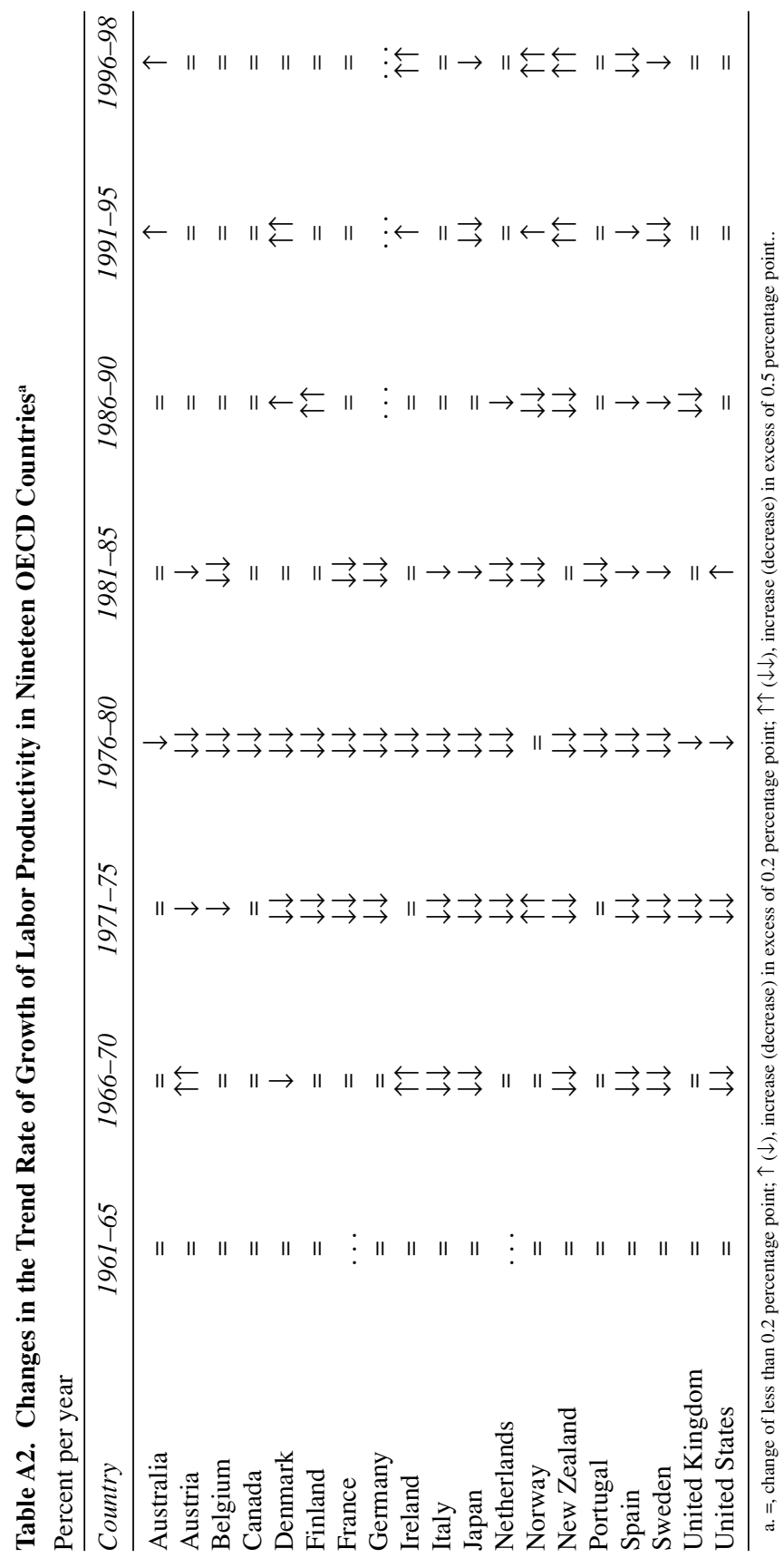




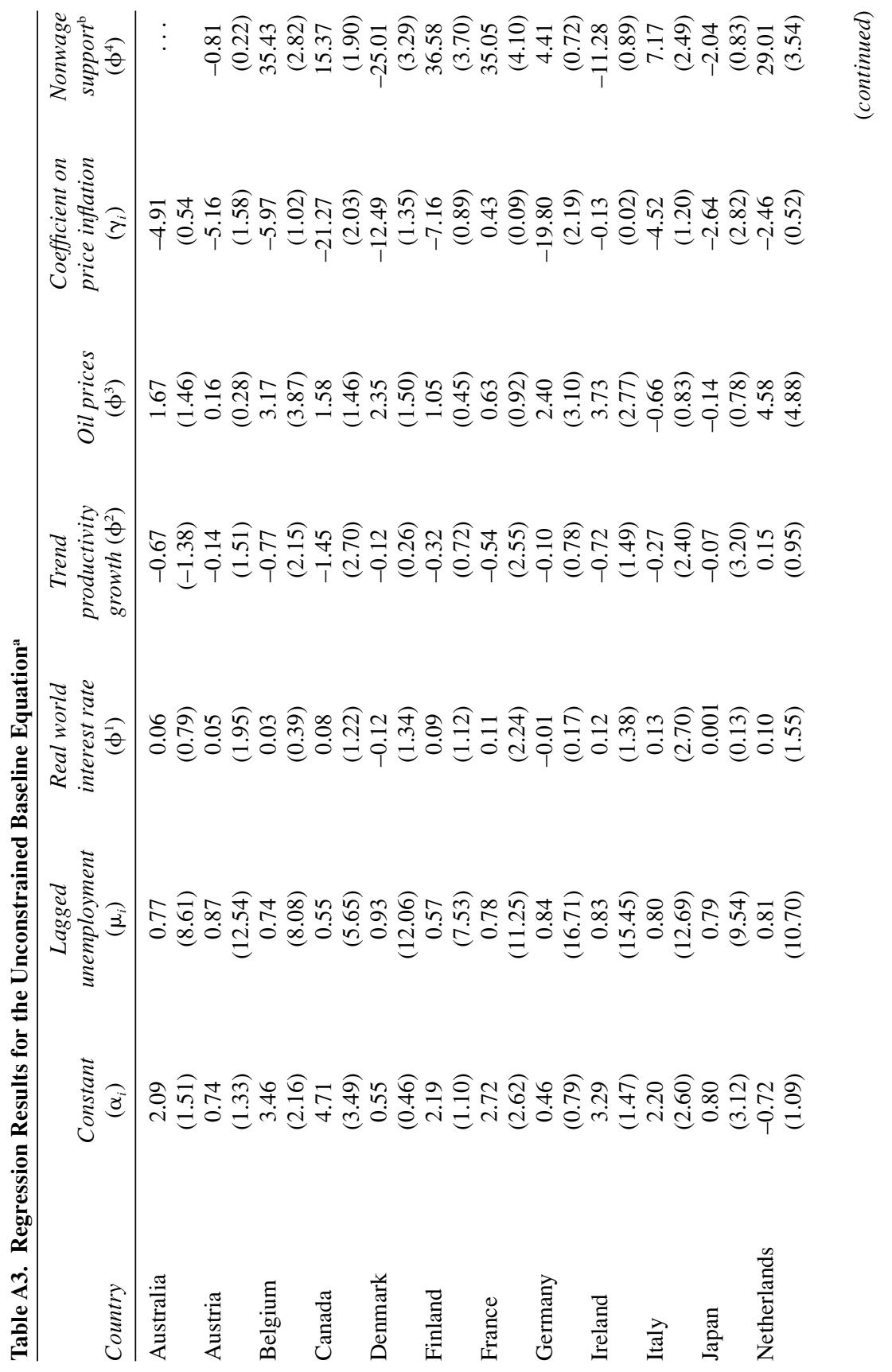




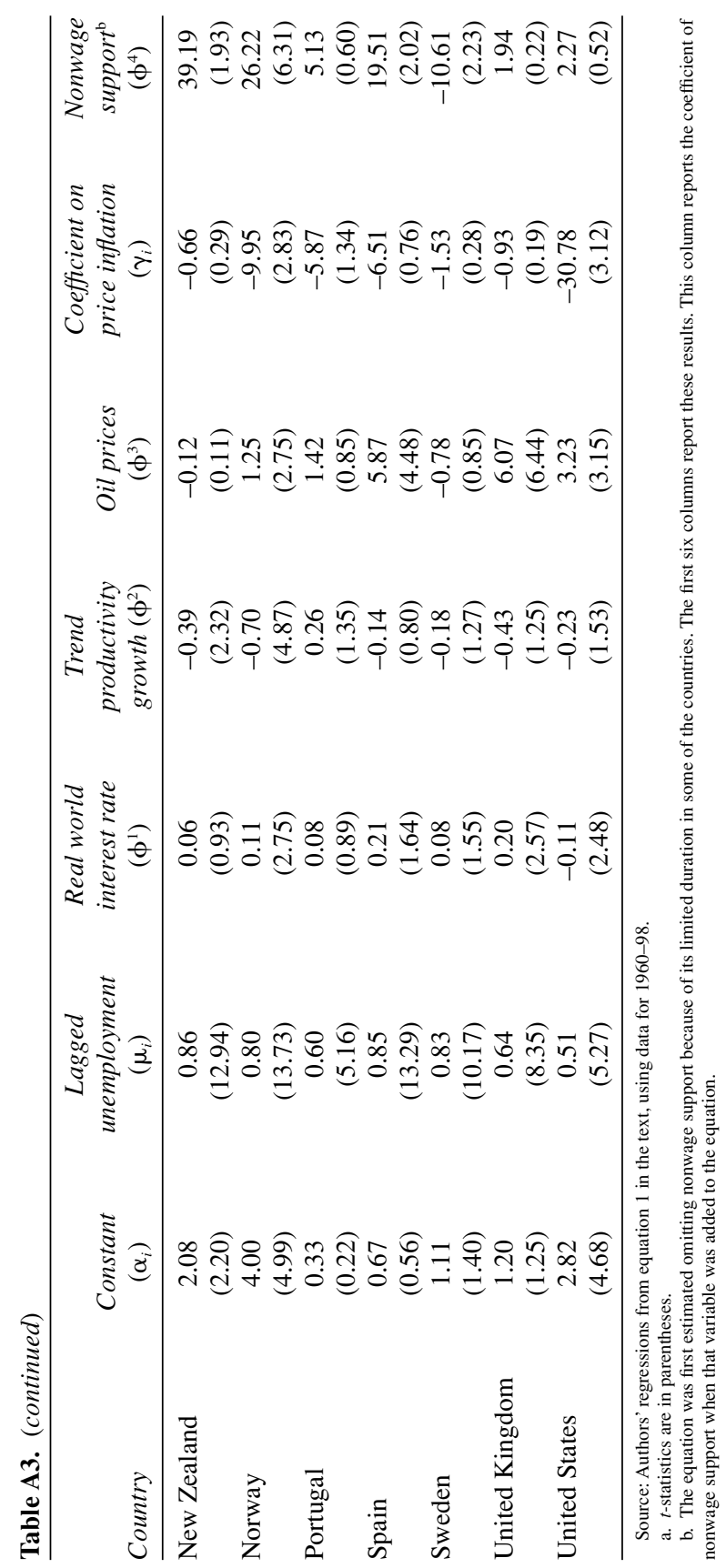


Figure A1. Unemployment and the Net Cost of Capital in the Group of Seven Countries Except Japan, 1960-99

Canada

Percent per year

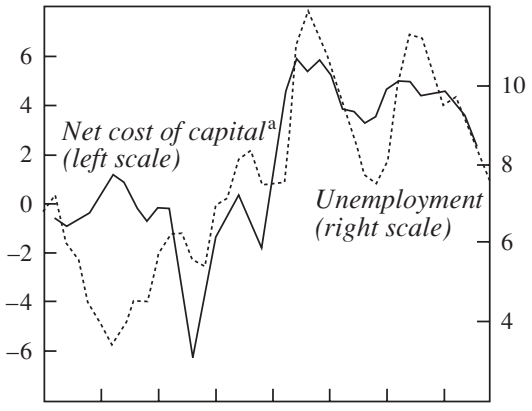

1965197019751980198519901995

Germany

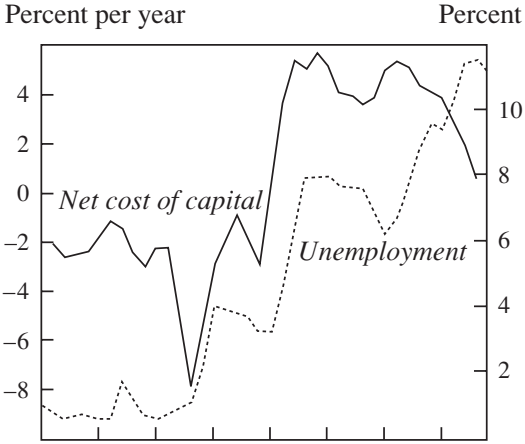

1965197019751980198519901995

United Kingdom

Percent per year

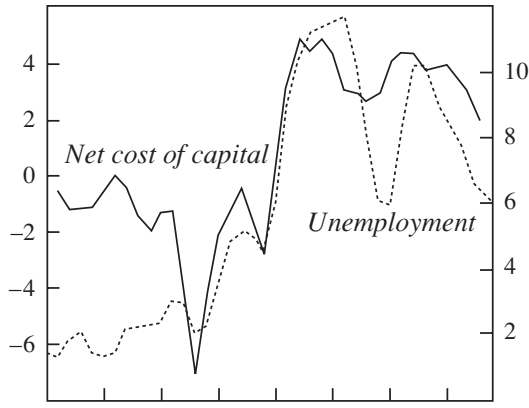

1965197019751980198519901995

\section{France}

Percent per year Percent

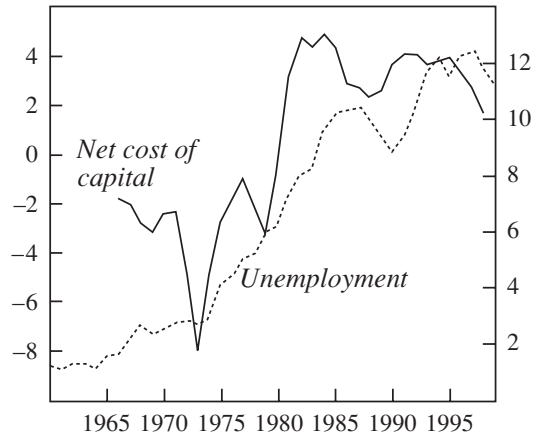

Italy

Percent per year Percent

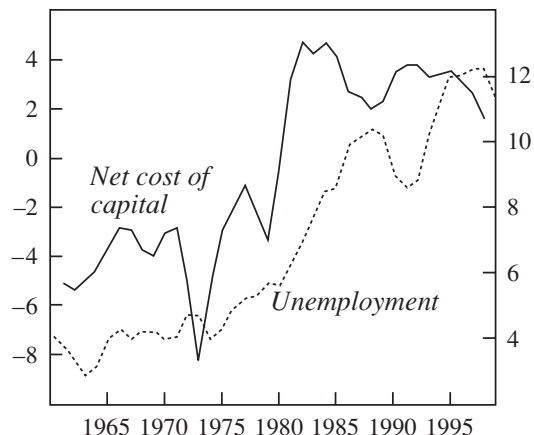

United States

Percent per year Percent

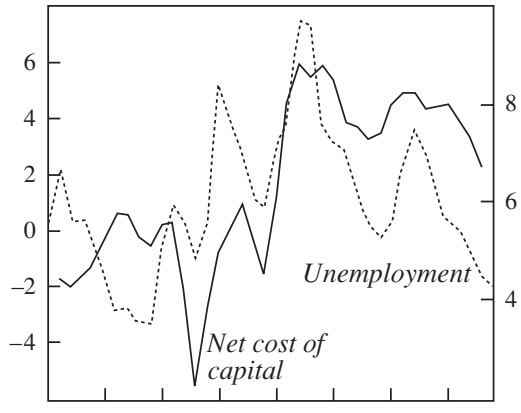

1965197019751980198519901995

Source: Authors' calculations using OECD data

a. Defined as $r^{*}-g$, or the world real interest rate minus the expected long-term growth rate of labor productivity. 
Figure A2. World Real Rate of Interest, 1960-99

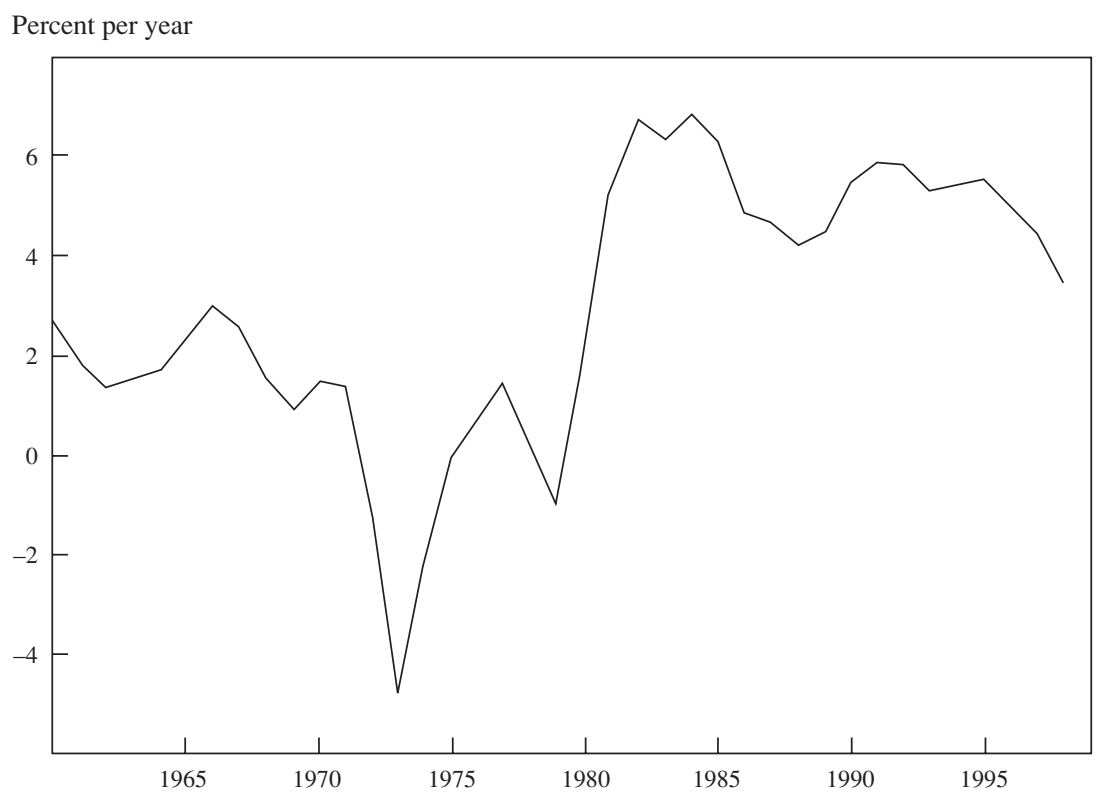

Source: OECD data. 
Figure A3. Unemployment and Income from Private Wealth in the Group of Seven Countries Except Japan, 1960-99

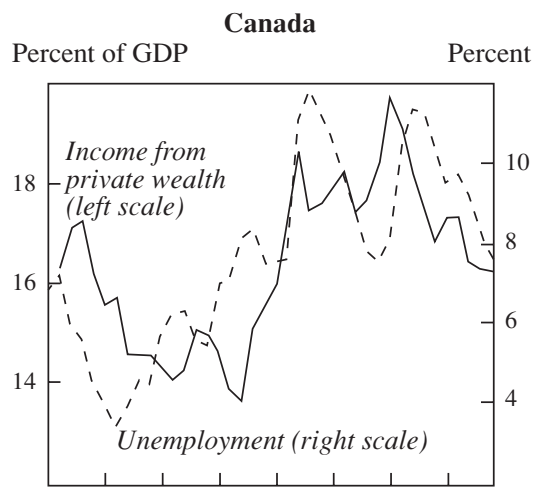

1965197019751980198519901995

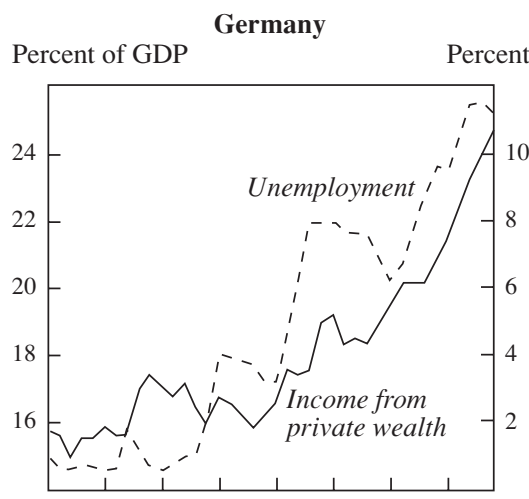

1965197019751980198519901995

United Kingdom

Percent of GDP

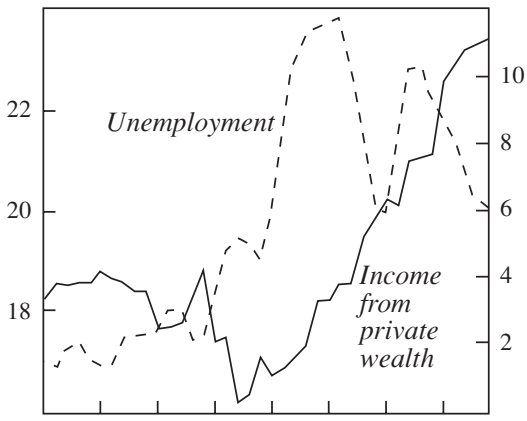

1965197019751980198519901995
France

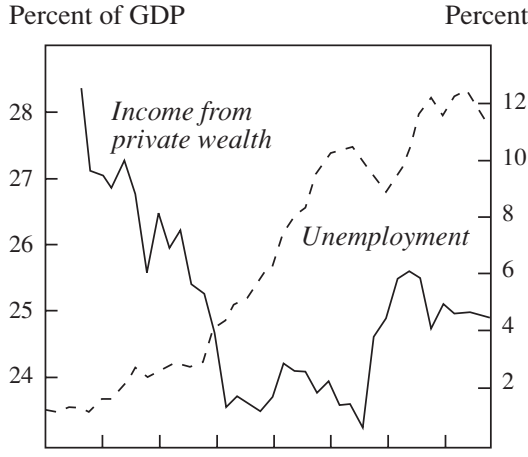

1965197019751980198519901995

Italy

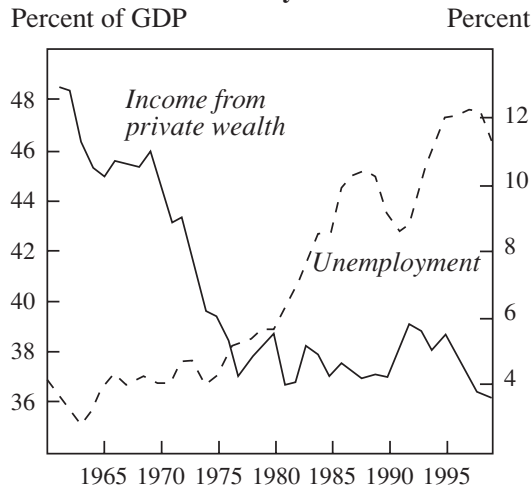

United States

Percent of GDP

Percent

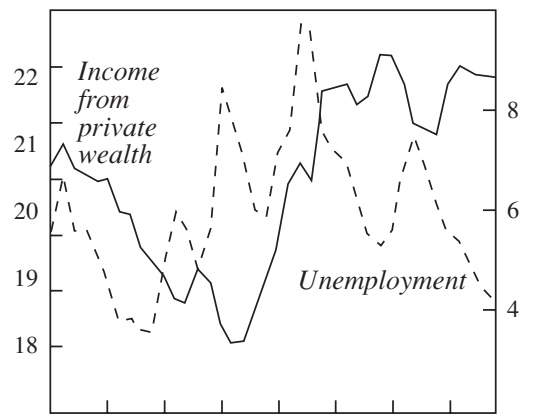

1965197019751980198519901995 
Figure A4. Unemployment and Social Spending in the Group of Seven Countries Except Japan, 1960-99

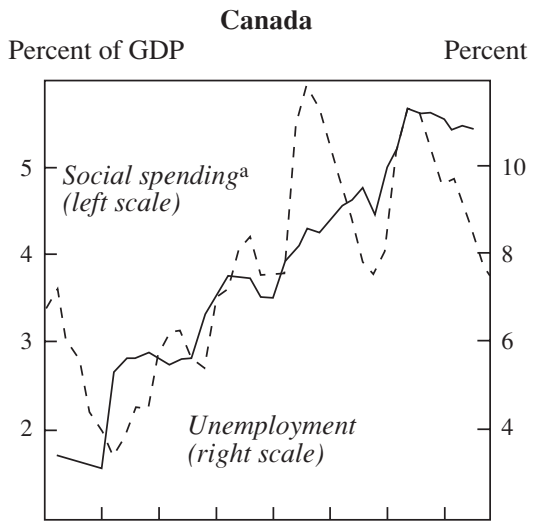

1965197019751980198519901995

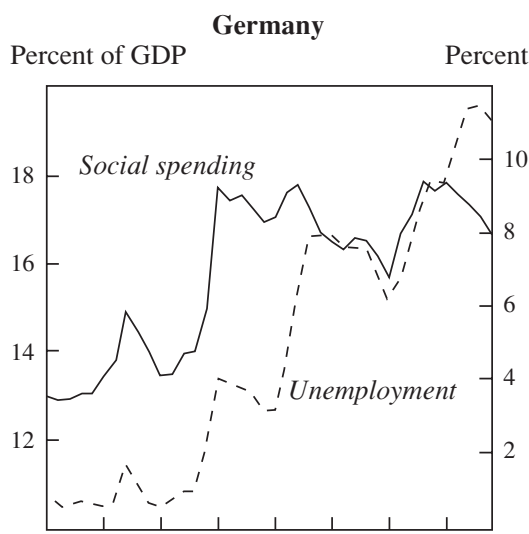

1965197019751980198519901995

United Kingdom

Percent of GDP

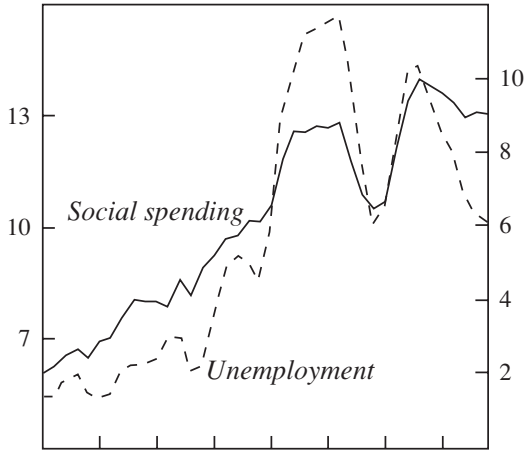

1965197019751980198519901995
France

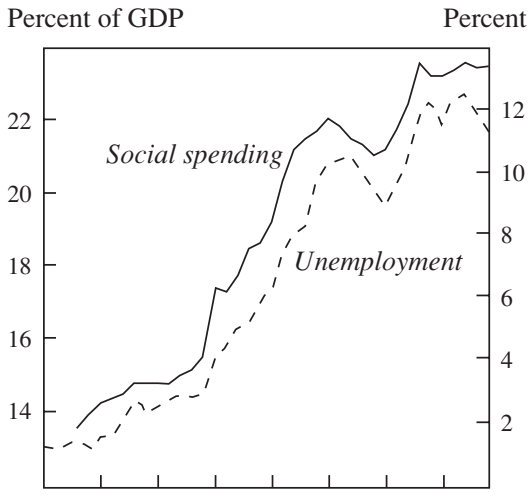

1965197019751980198519901995

Italy

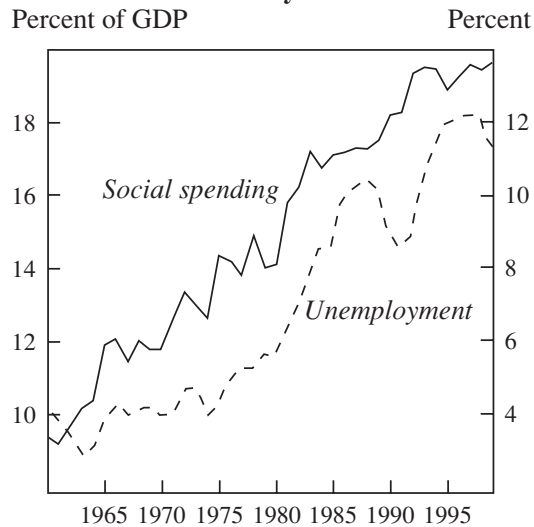

United States

Percent per year Percent

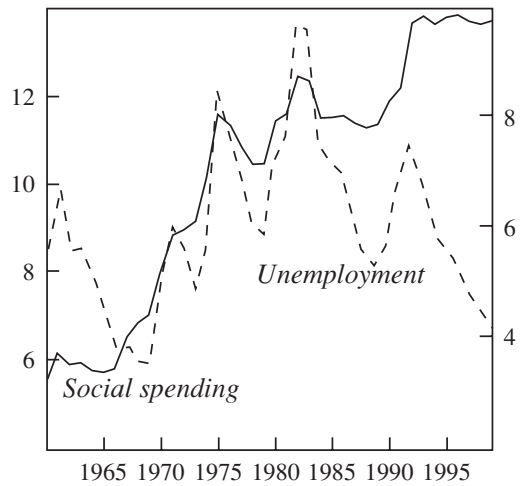


Figure A5. Investment Per Unit Capital and the Rate of Employment in the Group of Seven Countries Except Japan, 1960-99
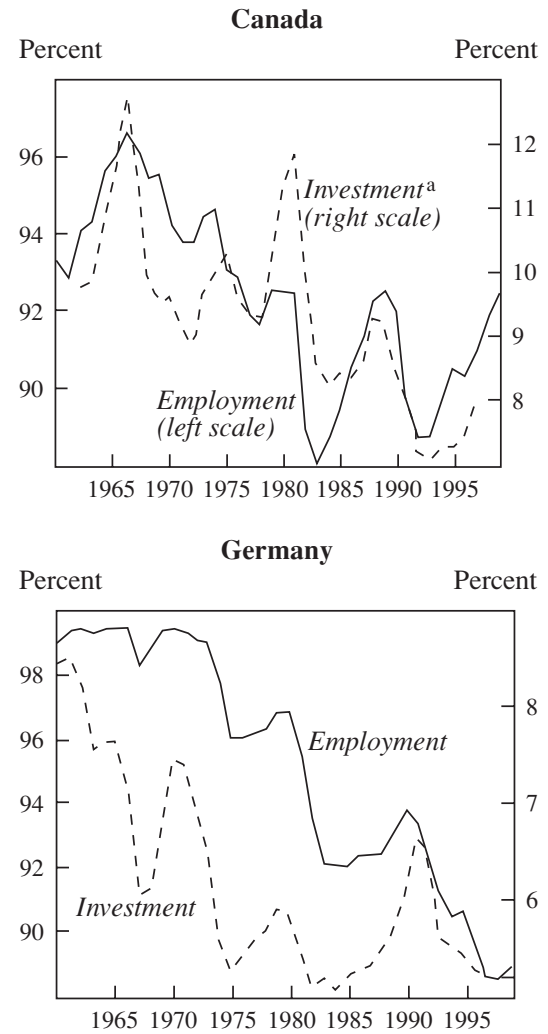

United Kingdom

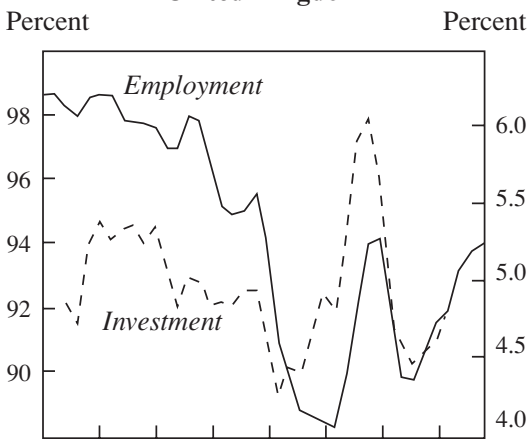

1965197019751980198519901995
France

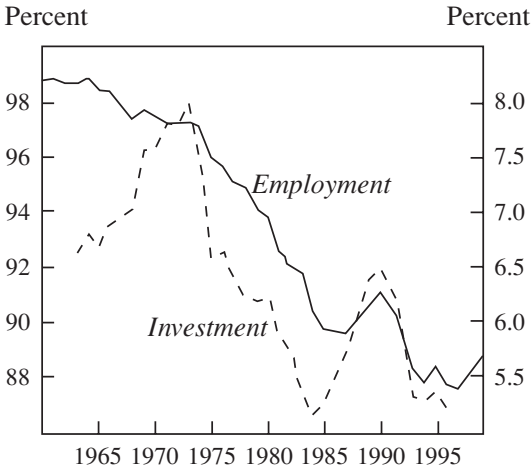

Italy

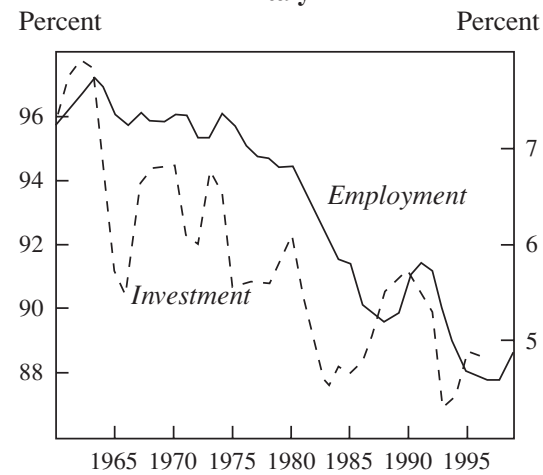

United States

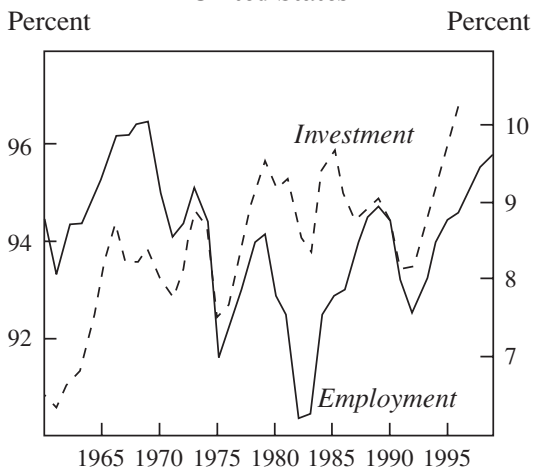

Source: Authors' calculations using OECD data. a. Defined as $I / K$. 
APPENDIX B

\section{Deriving the Role of Productivity and Tax Rates}

THE LOGIC of the derivation of the compound variable involving labor productivity and labor tax rates is as follows. The model can be viewed as determining the labor cost per employee, called "the wage to employers," as a ratio to productivity. Yet quitting behavior is a function of the wage after payroll taxes and income tax, called "the wage to employees," expressed as a ratio to income from private wealth. To disentangle this knot one needs first to divide both numerator and denominator in the latter ratio by the ratio of the employee wage to the employer wage, which makes the new numerator equal to the employer wage. One next divides both the new numerator and the new denominator by productivity, so that the employer wage in the numerator appears as a ratio to productivity, as desired. The final denominator is then income from private wealth as a ratio to productivity times the ratio of the employee wage to the employer wage. That is equal to nonwage income multiplied by the ratio of the employer wage to the employee wage and divided by productivity.

APPENDIX C

\section{A Dynamic System Underpinning the Hypothesized Asset Price-Employment Link}

A SIMPLE DYNAMIC SYSTEM to back the story in figure 4 is the open economy in Hoon and Phelps and in Phelps. ${ }^{44}$ A closed economy would also serve. Here, firms' assets are their employees, who are costly to train. There are rising marginal training costs. The real interest rate in terms of the economy's product is equal to the world real interest rate, $r^{*}$, which is taken to be fixed.

Output is an increasing function of "augmented" labor, $\Lambda_{t} N_{t}^{P}$, where $\Lambda_{t}$ denotes labor augmentation at time $t$ and $N_{t}^{P}$ denotes the number of employees engaged in production rather than training. We add fixed capital in a simple way by admitting imports of equipment on short-term lease from overseas suppliers with zero transport costs. When employees move from producing to training, they need the same equipment. The amount 
of capital per augmented employee, $K / \Lambda_{t} N$, is determined by the demand function, $\kappa$, which is decreasing in the given unit rental, $r^{*}+\delta$. Output per augmented employee allocated to production is given by $f\left[\kappa\left(r^{*}+\right.\right.$ $\delta)]$, and the rental per augmented employee is $\left(r^{*}+\delta\right) \kappa\left(r^{*}+\delta\right)$. Output and rental per unaugmented production worker are $\Lambda_{t} \varphi\left(r^{*}+\delta\right)$ and $\Lambda_{t} R\left(r^{*}+\delta\right)$, respectively.

In this setting, each identical firm, to maximize shareholder value, chooses the current hire rate, $h$, and its wage, $v$, to maximize a Hamiltonian function. That function involves the current proportion of employees engaged in training per hiree, given by $\beta(h)$, which is an increasing function of $h$; the mortality rate, $\theta$; the quit rate, $\zeta$, which is a function of the unemployment rate, $u$, of the current wage expected to be set at other firms relative to its own wage, $v^{e} / v$, and of income from private wealth, $y^{W}$, as a ratio to the wage; the shadow price the firm optimally awards itself for every current employee, $q$; and its current stock of employees, $N$. The current-value Hamiltonian is

$$
\begin{gathered}
\left(\Lambda_{t} \varphi\left(r^{*}+\delta\right)-\beta(h) \Lambda_{t} \varphi\left(r^{*}+\delta\right)-\Lambda_{t} R\left(r^{*}+\delta\right)-v\right. \\
\left.+q\left\{h-\zeta\left[(1-u) v^{e} / v, y^{w} / v\right]-\theta\right\}\right) N
\end{gathered}
$$

The necessary conditions for a maximum give the relationships behind figure 4 in the text. These three conditions together with the equilibrium (correct-expectations) condition, $v^{e}=v$, yield equations 1 through 3 . It will be convenient to write these equations in terms of the normalized wage, $v / \Lambda \varphi$; the normalized shadow price, $q / \Lambda \varphi$; and normalized income from private wealth, $y^{W} / \Lambda \varphi$. This introduces the actual and expected growth rate of $\Lambda$, to be denoted $\lambda$.

For a maximum, $q$ must satisfy the arbitrage equation

$$
\begin{aligned}
d(q / \Lambda \varphi) / d t= & -\left[1+h \beta^{\prime}(h)-\beta(h)-R / \varphi-v / \Lambda \varphi\right] \\
& +\left\{\zeta\left[1-u,\left(y^{w} / \Lambda \varphi\right) /(v / \Lambda \varphi)\right]+\theta+r^{*}-\lambda\right\} q / \Lambda \varphi .
\end{aligned}
$$

This equation says that a capital gain (loss) is needed to make up any shortfall (surplus) of the marginal profitability of employees, $\Lambda \varphi[1+h$ $\left.\beta^{\prime}(h)-\beta(h)-R / \varphi-v / \Lambda \varphi\right]$, over the economic interest and depreciation entailed, which is $q\left[\zeta+\theta+r^{*}-\lambda\right]$.

The optimal wage balances the marginal benefit of a small increase in the wage rate that results from the consequent reduction in the quit rate against the marginal cost in terms of the payroll on existing employees of the same small rise of the wage rate. This gives the condition 


$$
\begin{aligned}
v / \Lambda \varphi= & (q / \Lambda \varphi)\left\{(1-u) \zeta_{1}\left[1-u,\left(y^{w} / \Lambda \varphi\right) /(v / \Lambda \varphi)\right]\right. \\
& \left.+\left(y^{w} / \Lambda \varphi\right) /(v / \Lambda \varphi) \zeta_{2}\left[1-u,\left(y^{w} / \Lambda \varphi\right) /(v / \Lambda \varphi)\right]\right\} .
\end{aligned}
$$

Here both the left-hand and the right-hand sides have been multiplied by $v / \Lambda \varphi$ for typographical simplicity. The original right-hand side gives the two effects on the quit rate of an increase in pay, both effects multiplied by the normalized worth of the quits averted. The original left-hand side is equal to one.

The optimum scale of current hiring is at the point where the cost of speeding up by the amount of one new hire (as a ratio to the employee stock) would be just worth the gain per unit time from adding employees at that faster rate. The condition is $\beta^{\prime}(h)=q / \Lambda \varphi$, which is convenient to write in the form

$$
h=\phi(q / \Lambda \varphi) .
$$

where $\phi^{\prime}(q / \Lambda \varphi)>0$. Using that, we have the equation of motion for employment,

$$
d N / d t=\left\{\phi(q / \Lambda \varphi)-\zeta\left[1-u,\left(y^{w} / \Lambda \varphi\right) /(v / \Lambda \varphi)\right]-\theta\right\}(1-u),
$$

where, without loss of generality, units are chosen such that $N \equiv 1-u$.

\section{The Stationary Loci}

To obtain the asset price curve, which is the stationary locus for normalized $q$ in figure 4 , we need only set the left-hand side of equation $\mathrm{C} 1$ equal to zero, use equation $\mathrm{C} 3$ to substitute for $h$, and use equation $\mathrm{C} 2$, which implicitly gives $v / \Lambda \varphi$ as a function, say, $V^{s}\left(1-u, q / \Lambda \varphi ; y^{W} / \Lambda \varphi\right)$. This gives the stationary locus:

$$
\begin{aligned}
0= & -\left\{1+\phi(q / \Lambda \varphi) \beta^{\prime}[\phi(q / \Lambda \varphi)]-\beta[\phi(q / \Lambda \varphi)]\right. \\
& \left.-R / \varphi-V^{s}\left(1-u, q / \Lambda \varphi ; y^{W} / \Lambda \varphi\right)\right\} \\
& +\left\{\zeta\left[1-u,\left(y^{W} / \Lambda \varphi\right) / V^{s}\left(1-u, q / \Lambda \varphi ; y^{W} / \Lambda \varphi\right)\right]\right. \\
& \left.+\theta+r^{*}-\lambda\right\} q / \Lambda \varphi .
\end{aligned}
$$


Given $y^{W} / \Lambda \varphi$, the normalized share price can be shown to be decreasing in $1-u$. With a standard Blanchard-Yaari formulation of the accumulation of income from private wealth, Hoon and Phelps show that the longrun relationship is also negatively sloped.

To obtain the employment curve we proceed similarly, setting the lefthand side equal to zero and again using equation $\mathrm{C} 2$ to substitute $V^{S}(1-u$, $\left.q / \Lambda \varphi ; y^{W} / \Lambda \varphi\right)$ for $v / \Lambda \varphi$. This gives the stationary locus

$$
\begin{aligned}
0= & \{\phi(q / \Lambda \varphi) \\
& \left.-\zeta\left[1-u,\left(y^{w} / \Lambda \varphi\right) / V^{s}\left(1-u, q / \Lambda \varphi ; y^{w} / \Lambda \varphi\right)\right]-\theta\right\}(1-u) .
\end{aligned}
$$

Given $y^{W} / \Lambda \varphi$, the employment variable can be shown to be increasing in the normalized shadow price. Again, with a Blanchard-Yaari formulation, the long-run relationship is also positively sloped.

\section{Dynamics}

A common shortcut in analyzing dynamic systems takes the slowermoving of the two state variables, here the income from private wealth variable, to be temporarily constant and analyzes the dynamics of the fastermoving variable, employment, accordingly. Here, this subsystem is simply equations $\mathrm{C} 1$ and $\mathrm{C} 4$, after making the substitutions for $v$ and $h$ from equations $\mathrm{C} 2$ and $\mathrm{C} 3$ :

$$
\begin{aligned}
d(q / \Lambda \varphi) / d t= & -\left\{1+\phi(q / \Lambda \varphi) \beta^{\prime}[\phi(q / \Lambda \varphi)]-\beta[\phi(q / \Lambda \varphi)]\right. \\
& \left.-R / \varphi-V^{s}(1-u, q / \Lambda \varphi)\right\} \\
& +\left\{\zeta\left[1-u,\left(y^{W} / \Lambda \varphi\right) / V^{s}\left(1-u, q / \Lambda \varphi ; y^{w} / \Lambda \varphi\right)\right]\right. \\
& \left.+\theta+r^{*}-\lambda\right\} q / \Lambda \varphi,
\end{aligned}
$$

$$
\begin{aligned}
& d(1-u) / d t=\{\phi(q / \Lambda \varphi) \\
&\left.-\zeta\left[1-u,\left(y^{W} / \Lambda \varphi\right) / V^{s}\left(1-u, q / \Lambda \varphi ; y^{w} / \Lambda \varphi\right)\right]-\theta\right\}(1-u) .
\end{aligned}
$$

Analysis of this medium-run system gives the equilibrium motion along a negatively sloped saddle path leading (from either side) to the intersection of the asset price curve and the employment curve corresponding to the given $y^{W} / \Lambda \varphi$, dubbed here the medium-term rest point. 
One kind of shock to this system is a sudden increase in the expected rate of labor augmentation, $\lambda$. Analysis of this system yields the intuitive result that such a shift of $\lambda$ generates an upward shift of both the asset price curve and the saddle path, hence a jump in the normalized share price, followed by a gradual sinking of that variable to its higher medium-term rest point value and a gradual rise of employment toward its likewise higher medium-term rest point value.

Even if real-life economies fluctuated only up and down this saddle path, there might be a reason to add a normalized stock market indicator to the employment growth equation. Such an indicator could serve as a proxy for omitted asset stocks, such as customers and even fixed capital, which is rarely well measured.

The shock highlighted in figure 4 brings out the major value added of a stock market indicator. This shock is a sudden anticipation of a onetime shift at a future date in the path of productivity and thus of profits per unit of assets. That shock requires a difficult analysis with respect to the aftermath of the shock, since the quantum jump in productivity, once it actually occurs, has a quantum effect on the wealth-to-productivity ratio, and therefore that ratio can no longer be held constant for analytical simplicity. But our interest is only in the existence of an expansion phase following the sudden anticipation of the future productivity shift. The reasoning behind our conclusions that the asset price immediately jumps and that employment, if initially steady, will then be rising until the moment of the productivity shift appears inescapable. In such a bubble scenario, a normalized stock market indicator can serve to pick up the expectation of the future parameter shift-in our example, the productivity shift.

\section{APPENDIX D}

\section{Share Prices and Company Employment}

THIS APPENDIX ANALYZES company data for Canada (companies in the Toronto Stock Exchange index), France (the CAC40), Germany (the DAX), Italy (the Milan Stock Exchange index), the United Kingdom (the FT index), and the United States (the Dow Jones Industrial Average). 
Table D1. Regression Results Using Company Data ${ }^{a}$

\begin{tabular}{lcccccc}
\hline Independent variable & & & & & United & United \\
& Canada & France & Germany & Italy & Kingdom & States \\
\hline Logarithm of the real share price & 0.12 & 0.03 & 0.02 & -0.01 & 0.14 & 0.06 \\
(not normalized) & $(3.36)$ & $(2.09)$ & $(1.56)$ & $(0.87)$ & $(2.87)$ & $(3.01)$ \\
Net profit margin & 0.29 & -0.16 & -0.06 & -0.00 & -0.59 & 0.07 \\
& $(1.89)$ & $(0.78)$ & $(0.14)$ & $(0.17)$ & $(1.11)$ & $(0.34)$ \\
Change in the growth rate of & -1.23 & 0.16 & 0.20 & 0.42 & -1.72 & 0.44 \\
nominal GDP & $(2.14)$ & $(0.57)$ & $(1.74)$ & $(1.95)$ & $(1.44)$ & $(0.85)$ \\
\hline
\end{tabular}

Source: Data from Hoover's Online and Datastream.

a. The dependent variable is employment growth in a sample of companies in the country in question. $t$-statistics are in parentheses.

This has the advantage of looking at changes in employment over time for units that share the same macroeconomic environment. We then test for the effect of real share prices $p^{S}$ and profits (net profit margin, $p r$ ) on growth in employment $(N)$. In addition, we allow employment growth to be affected by the change in the growth rate of nominal GDP, $Y$, which proxies for (macroeconomic) demand shocks. We estimate for each of the countries an equation of the form:

$$
\frac{\Delta N_{i t}}{N_{i t}}=\tau_{i}+\alpha_{1} \log p_{t}^{S}+\alpha_{2} p r_{i t}+\alpha_{3} \Delta^{2} Y_{i t}+\varepsilon_{i t},
$$

where $\tau$ denotes a company-specific fixed effect. The results for the period 1987-98 are reported in table D1.

Notice that the real share price is significant and correctly signed in all countries except Italy, whereas the profit margin is significant only in Canada. The demand shock is both correctly signed and significant only in Germany and Italy; it is incorrectly signed in Canada and the United Kingdom. 


\section{Comments and Discussion}

Olivier Blanchard: This is an ambitious paper. ${ }^{1}$ It extends the general framework developed by Edmund Phelps and a number of coauthors in the past, and it reexamines the evolution of unemployment in the OECD countries over the past forty years. It then offers a new mechanism through which the emergence of the "new economy" may be affecting equilibrium unemployment. Finally, it examines whether this new mechanism can indeed explain the declines in unemployment observed in a number of OECD countries in the 1990s. My comments will follow a parallel structure, starting with a discussion of the general framework, then turning to a discussion of the new mechanism, and finally offering my own interpretation of the decline in unemployment in two countries, Ireland and the Netherlands.

The emerging consensus. A reading of this and other recent papers on the evolution of unemployment reveals the emergence of a broad consensus-good news after some thirty years of research on the increase in European unemployment. The consensus focuses on the joint role of shocks and institutions and on their interactions. It goes roughly as follows.

Far from being an immutable constant, the natural rate of unemployment (also called the NAIRU, or the structural rate, or the equilibrium rate; the semantics are far from settled here) moves in response to shocks. Labor market institutions also matter. They do so directly, by affecting the under-

1. I thank Justin Wolfers for useful discussions. 
lying mean to which the natural rate eventually returns. Also, and more important, they do so by affecting the size and the persistence of movements in the natural rate in response to shocks.

This consensus encompasses many approaches that were once seen as largely incompatible, for example:

- The work by Michael Bruno and Jeffrey Sachs, ${ }^{2}$ which focused on the effects of adverse oil and productivity shocks and their interaction with real and nominal wage rigidities. For example, the effect of an increase in the price of oil on the natural rate of unemployment is likely to depend on whether wage negotiations are centralized or decentralized. Centralized negotiations make it easier to coordinate a slowdown in wages in response to an aggregate shock.

-The work by Phelps himself on structural slumps, ${ }^{3}$ which resulted in a model of the labor market based on imperfections on both the supply and the demand sides. Phelps used this approach to look at the effects of a number of shocks on unemployment. The argument developed in this paper is an example of how this approach can be used to think about movements in unemployment. The authors of this paper argue that, in a number of countries, the desire of firms to build a consumer base and a pool of trained workers for the future has led them to increase hiring at a given real wage, leading to a decline in unemployment today.

- The work by Lawrence Summers and myself on hysteresis, ${ }^{4}$ which focused on the persistence of deviations of the unemployment rate from its mean. Our initial focus was on the objective function of the employed workers and its effect on bargaining outcomes. Under the influence of Richard Layard and Stephen Nickell, in particular, this line of research has increasingly focused on the role of the unemployed and, in particular, of long-term unemployment, in wage determination. If, for example, labor market institutions lead to unemployment characterized by individual spells of long duration, the risk that sustained high unemployment will lead to the disenfranchising of the long-term unemployed and, by implication, low upward pressure on wages and a slow decrease in unemployment, is higher. Our initial focus was on the persistent effects of shifts in aggregate demand on unemployment. But the argument extends to the

2. Bruno and Sachs (1985).

3. Phelps (1994).

4. Blanchard and Summers (1986). 
effects of any shock that increases unemployment, from oil to productivity shocks.

This broad "consensus" approach has proved useful in describing trends in unemployment across the OECD countries over the last forty or so years. Let me briefly review what has been done, what has been learned, and how the specification offered in this paper relates to other specifications in the literature.

Denote the unemployment rate in country $i$ in year $t$ by $u_{i t}$. Denote the vector of measures of shocks and the vector of measures of institutions in country $i$ in year $t$ by $S_{i t}$ and $I_{i t}$, respectively.

A generic specification would allow $u_{i t}$ to depend on current and lagged values of $S_{i t}$, of $I_{i t}$, and of terms capturing interactions between each shock in $S_{i t}$ and each institution in $I_{i t}$. Obviously, this is far too much to ask of the data. Thus the specifications explored in recent papers must be seen and evaluated as rough shortcuts to this more appealing, but unattainable, specification.

One of the first specifications along these lines was offered by Phelps. ${ }^{5}$ It took the form

$$
u_{i t}=c_{i}+b_{i} u_{i t-1}+\left(S_{i t} \beta\right) d_{i}+\varepsilon_{i t},
$$

where $\beta$ is a vector of coefficients of the same dimension as the vector of shocks, and $c_{i}, b_{i}$, and $d_{i}$ are scalars.

The unemployment variable was allowed to depend on its own lagged value and on a number of variables capturing "shocks," from oil prices, to tax changes, to changes in government debt. (The list was somewhat different from that in the present paper. In particular, it did not include productivity growth, to which this paper assigns a large role.) Institutions were not explicitly introduced in the specification, but the constant term $c_{i}$, the effects of a given vector of shocks $d_{i}$, and the degree of persistence $b_{i}$ were all allowed to have country-specific values, capturing implicitly the role of different institutions in different countries. The estimated response of the natural rate to shocks was smallest in Japan and the United States, and strongest in the Netherlands and Germany.

In a recent paper, Justin Wolfers and I offered an alternative specification in which we explicitly allowed for shocks, institutions, and interactions. ${ }^{6}$ Our basic specification took the form

6. Blanchard and Wolfers (2000). 


$$
\bar{u}_{i t}=c\left(X_{i t}\right)+\left(S_{i t} \beta\right) d\left(X_{i t}\right)+\varepsilon_{i t} .
$$

Our specification differed from the Phelps specification in two ways. First, we forced the constant and the effect of a given vector of shocks$c_{i}$ and $d_{i}$, respectively, in Phelps's specification- to be linear functions of our measures of labor market institutions. Second, because we were skeptical that we could separately estimate the effect of institutions on both the size and the dynamic effects of shocks on unemployment, we estimated a static specification using five-year averages, rather than a dynamic specification with annual data as Phelps had done. We found that our measures of shocks-in particular, measures of productivity growth, of real interest rates, and of labor hoarding (more on this below) - could account for the general evolution of unemployment over the last thirty years. We also found that labor market institutions could account for differences in the response of unemployment to shocks across countries. The effect of shocks on the natural rate was weakest in Japan and the United States and strongest in Spain. Higher employment protection and a longer duration of unemployment benefits both led to larger effects of shocks on the natural rate. Time variation in institutions did not seem to help in explaining the evolution of unemployment.

The present paper does what we had shied away from doing. It attempts to estimate the separate effect of institutions on the size and the persistence of the effects of shocks on unemployment. Although the authors estimate their equation in two steps (first obtaining country-specific coefficients, then regressing these coefficients on institutions), we can think of their specification as being of the form:

$$
u_{i t}=c\left(X_{i t}\right)+b\left(X_{i t}\right) u_{i t-1}+\left(S_{i t} \beta\right) d\left(X_{i t}\right)+\varepsilon_{i t},
$$

This specification is clearly more appealing than ours. It is obviously still far short of what one would want, however. Different shocks are likely to have different dynamic effects on unemployment, some building up before decreasing, others decreasing from the start. Some institutions may have a strong impact on the effects of some shocks on unemployment, but not on the effects of others. The authors' specification allows for neither of these differences. Even so the specification may be asking more of the data than the data can tell. I did not have access to the authors' data set in time to explore the robustness of their results. But based on an exploration using the data set from Blanchard and Wolfers, some of the results do not appear very robust. In particular, the ability of the data to clearly 
separate the impact of institutions on the size versus the persistence of the effects of shocks is limited.

In short, something has been learned from these panel data regressions, namely, the fact that one can give a good statistical account of the evolution of OECD unemployment rates as a function of shocks, institutions, and their interactions. This was not obvious ex ante. My reading of the results from this and other papers goes roughly as follows:

-As to shocks: the slowdown in productivity growth that started in the 1970s, the movements in oil prices, and the downs and ups of real interest rates clearly have played a role in the overall evolution of the natural rate of unemployment.

-As to institutions: some labor market institutions appear to lead to larger or longer effects of shocks on unemployment. Among these, the duration of unemployment benefits, the decentralization of wage negotiations, and the degree of employment protection appear to be the most important.

It should be clear, however, that only so much can be learned from such panel data unemployment regressions. What specific shocks and what specific institutions matter, and how and why they matter, are probably beyond the confines of what we can learn from such an empirical exercise. Progress must come from looking at a broader set of macroeconomic implications, a broader set of variables, and tighter, less agnostic, specifications.

Indeed, within this broad consensus, many unanswered questions remain. I shall focus on three of these, all of them triggered by the results of this paper.

First, a usual finding, confirmed by the results presented in the paper's table 1 , is that changes in productivity growth appear to play an important role in explaining the evolution of the natural rate of unemployment. The initial increase in unemployment in the 1970s was associated with a decrease in the underlying rate of total factor productivity growth. Recent decreases in unemployment, for example in Ireland, or most recently in the United States, appear to be due in part to faster productivity growth. The question is why.

The authors of this paper argue that productivity growth matters through the user cost of capital. The true cost of capital is equal, they argue, to the real interest rate minus the rate of productivity growth. The slower that growth, the higher the user cost. I am skeptical of this inter- 
pretation on both theoretical and empirical grounds. On theoretical grounds, the argument appears to rely on disembodied technological progress, so that the marginal product of a given machine increases with overall productivity over time. This is probably not a good assumption. On empirical grounds, the fact that the coefficient on $g$ is consistently three to five times larger in absolute value than the coefficient on $r$ in their table 1 suggests that more is at work than just the effect of $(r-g)$.

My own interpretation, which is far from original, is that, when underlying total factor productivity growth slows down, it takes some time for both workers and firms to adjust to the new reality. During that time, wages rise too fast relative to total factor productivity growth, leading to a decrease in employment, both directly and through lower profits and lower capital accumulation. The exact nature of this channel, what it depends on, and how long it takes for aspirations to become consistent with reality, remain, however, largely unexplored issues.

Second, another typical finding, also present in the authors' table 1, is that real interest rates appear to play an important role in accounting for the evolution of the natural rate of unemployment. (This stylized fact was more controversial ten years ago. It now seems widely accepted.) In these panel data regressions, high real interest rates are the main explanator of why the natural rate of unemployment remained high in Europe in the 1980s. My preferred explanation is that high real interest rates lead to a higher user cost, which leads to lower capital accumulation, which in turn leads to lower employment. There are other possible explanations, for example the idea (also explored by $\mathrm{Phelps}^{7}$ ) that the real interest rate affects the desired markup of firms, and in turn equilibrium unemployment. I find these less persuasive.

On both econometric and conceptual grounds, however, the question arises of where these movements in real interest rates come from. Whether they come from shifts in the demand for capital, or from shifts in the supply of capital, surely has different implications for the evolution of unemployment. If they come largely from shifts in monetary policy-as seems plausible during a period characterized by disinflation policies, the creation of the euro, and so on-does this not imply that monetary policy can have long-lasting effects, not only on the deviation of the actual unemployment rate from the natural rate but also on the natural rate itself? Again, this is an important issue, on which there is surprisingly

\section{Phelps (1994).}


little work. (This line of argument is related, but not identical, to the study by Laurence Ball of the effects of aggregate demand on unemployment in the long run. ${ }^{8}$ )

Third, it is ironic (or perhaps not) that, even as we are starting to have a coherent story for what happened in the 1970s and the 1980s, the 1990s remain largely a mystery. It is hard to believe that, by the early 1990s, aspiration wages had not adjusted to lower productivity growth. And since the crisis in the European monetary system of the early 1990s, real interest rates have declined. Both these factors should have led to lower unemployment. Yet in most (but not all) countries, unemployment remained high for most of the 1990s. Only in the last couple of years have most countries started to see unemployment decline. With these questions in mind, let me turn to the second issue I want to take up, namely, the tentative explanation for the evolution of unemployment in the 1990s offered in the present paper.

The new economy and unemployment. In an attempt to explain why unemployment had remained high during the 1990s, I offered, in a 1997 Brookings Paper, my own "mystery shock." ${ }^{\circ}$ From the large decrease in the labor share in a number of European countries, and the underlying movements in capital, labor, and wages, I argued that, at least in continental Europe, we were seeing a decrease in labor hoarding, perhaps due to a decrease in workers' bargaining power. This dishoarding, I argued, explained both why unemployment remained high and why profits were sharply increasing. I ventured to forecast that the effects of such dishoarding would eventually be favorable for employment: higher profits would lead to higher capital accumulation, and higher employment down the road. Three years later, with unemployment indeed coming down, I still believe that basic argument.

Focusing more on the recent declines in unemployment, the authors of this paper offer a different "mystery shock," namely, the anticipation of a bright economic future leading to lower unemployment today. This is the time, their argument goes, for firms to invest in and train workers and to invest in a large consumer base. This means being willing to charge a low price (to attract customers) or to pay a high wage (to attract workers). In both cases this translates into a favorable shift in labor demand: at a given level of employment, firms are willing to pay a higher real product wage,

\footnotetext{
8. Ball (1999).

9. Blanchard (1997).
} 
either because they are willing to charge low prices, or because they are willing to pay high nominal wages. It is this favorable shift in demand that is leading to a decrease in unemployment.

The argument is clear. But is it plausible, and are the effects large enough to account for the declines in unemployment we have observed? I remain skeptical.

Consider the argument that firms want to hire workers today so as to have time to train them and have them ready when demand will be higher. This makes sense only if the skills the workers are going to acquire are firm specific. Otherwise, trained workers will always extract their full marginal product, and there is no point for a particular firm in hiring and training them today. Are the skills required of the new economy highly firm specific? Although I know of no hard evidence, anecdotal evidence seems to point the other way. To draw on our own experience as employers, the widespread adoption of computer programs such as Word and Excel makes it much easier to hire temporary workers and get them up to speed than in the past. Perhaps more convincing, the wage differential between skilled and unskilled workers, which had increased steadily for at least twenty years in the United States, has stopped growing since roughly 1995, that is, before the "new economy" started occupying the scene. The timing is not good for the hypothesis.

I find more attractive the idea that some firms have become more eager to create and extend their customer bases. After all, many e-commerce firms sell their products at a zero price; equivalently, their product wage is infinite. The goal of these firms is clearly to develop a customer base, from which they hope to extract profits in the future. This is, however, clearly true only for a small segment of the economy, and the empirical issue is how large a shift in labor demand this can generate. I am skeptical that it can explain enough.

The paper provides supporting evidence in the form of Granger causality tests, showing that movements in stock prices help predict decreases in unemployment. Such evidence is indeed consistent with their story, but it hardly settles the issue. Most of the factors that might lead to a decrease in unemployment are likely to be associated with an increase in stock values, and because the stock market is forward looking, this increase is likely to take place long before the full decrease in unemployment.

An implication of the authors' theory, which may help differentiate it from any theory in which good news about the future leads to more output and employment today, has to do with the behavior of labor produc- 
tivity. According to their theory, firms hire workers in anticipation of higher demand in the future, and this leads to a decline in current labor productivity. Stock price increases should therefore be associated with a decrease in labor productivity for some time. In this light, the evidence in table 13, in which the authors show that stock prices "cause" (in the sense of the Granger test) the residual from a regression of unemployment on output, is intriguing. The sign of the Granger causation and the shape of the estimated relation are not reported, however, so it is difficult to assess this evidence, but this is clearly worth pursuing in future work.

Ireland and the Netherlands. Two countries that have seen a dramatic decline in their unemployment rate over the last fifteen years are Ireland and the Netherlands. In Ireland the unemployment rate, which stood at 17 percent in 1986, now stands below 6 percent. In the Netherlands the unemployment rate has come down from 11 percent in 1983 to less than 3 percent today. Can we explain what happened in these two countries, and how does it relate to the analysis presented in this paper?

In both cases the proximate cause of the decrease in unemployment is not hard to find. Take first a short theoretical detour. Recall that, for an economy to grow along a balanced path, the rate of real wage growth must be equal to the rate of technological progress, which we can compute by constructing the Solow residual for each year and dividing it by the share of labor. Call the rate of technological progress the rate of warranted wage growth. What has happened in both countries is that, starting in the mid-1980s, actual wage growth has remained below warranted wage growth. This is shown in the top panel of figure 1 below for Ireland, and in the top panel of figure 2 for the Netherlands. In each figure the solid line in the top panel depicts the logarithm of the real wage since 1969 (that is, the integral of actual real wage growth since 1969). The dashed line shows the logarithm of the warranted real wage (that is, the integral of warranted real wage growth since 1969) over the same period. Both log variables are normalized to zero in 1969. Both figures show how wages, which had increased above warranted wages in the 1970s, turned around in the early 1980s and have remained consistently lower than warranted wages since then.

One would expect such wage moderation to have two effects over time. The first is to increase profits and investment. The second is to lead firms to increase the ratio of labor to capital in their production. This is indeed exactly what one observes in the data, as the bottom panels of figures 1 
Figure 1. Ireland: Actual and Warranted Real Wages and Employment-Capital Ratio, 1969-94
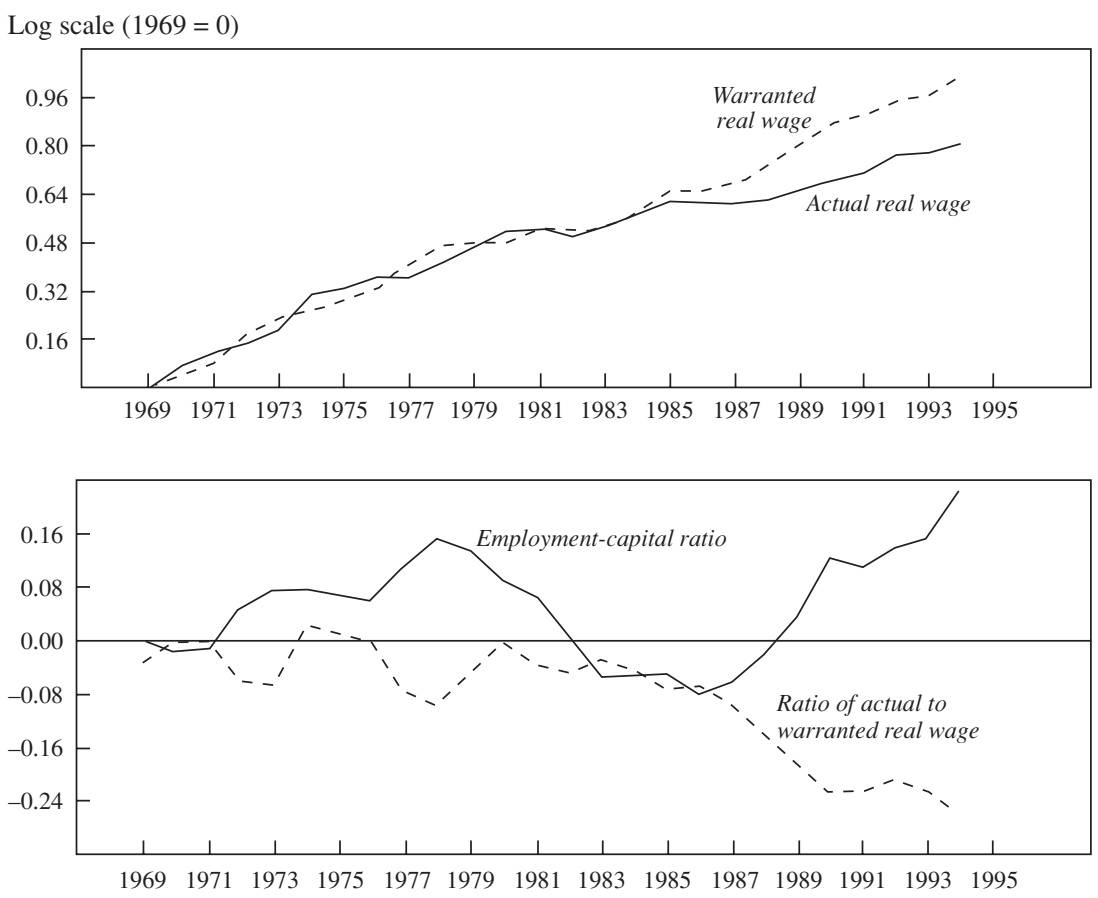

Source: Author's calculations using data from the OECD Business Letter database.

and 2 show. These graphs show, as the dashed line, the trends in the real wage relative to the warranted real wage (more specifically, the log of the real wage minus the log of the warranted real wage, $\left.w-w^{*}\right)$. They also show, as the solid line, the trends in the ratio of employment-adjusted for technological progress - to capital (more specifically, the log of employment minus the $\log$ of the warranted real wage, minus the log of the capital stock, $n-w^{*}-k$ ). In both countries, firms, which moved away from labor in the 1970s, turned around in the mid-1980s. Since the mid-1980s, higher capital accumulation and a higher labor-capital ratio have both led to a steady increase in employment and a steady decrease in unemployment.

One might wonder whether the pattern in figures 1 and 2 is specific to those countries that have succeeded. The answer appears to be yes. As an 
Figure 2. Netherlands: Actual and Warranted Real Wages and Employment-Capital Ratio, 1969-95

Log scale $(1969=0)$
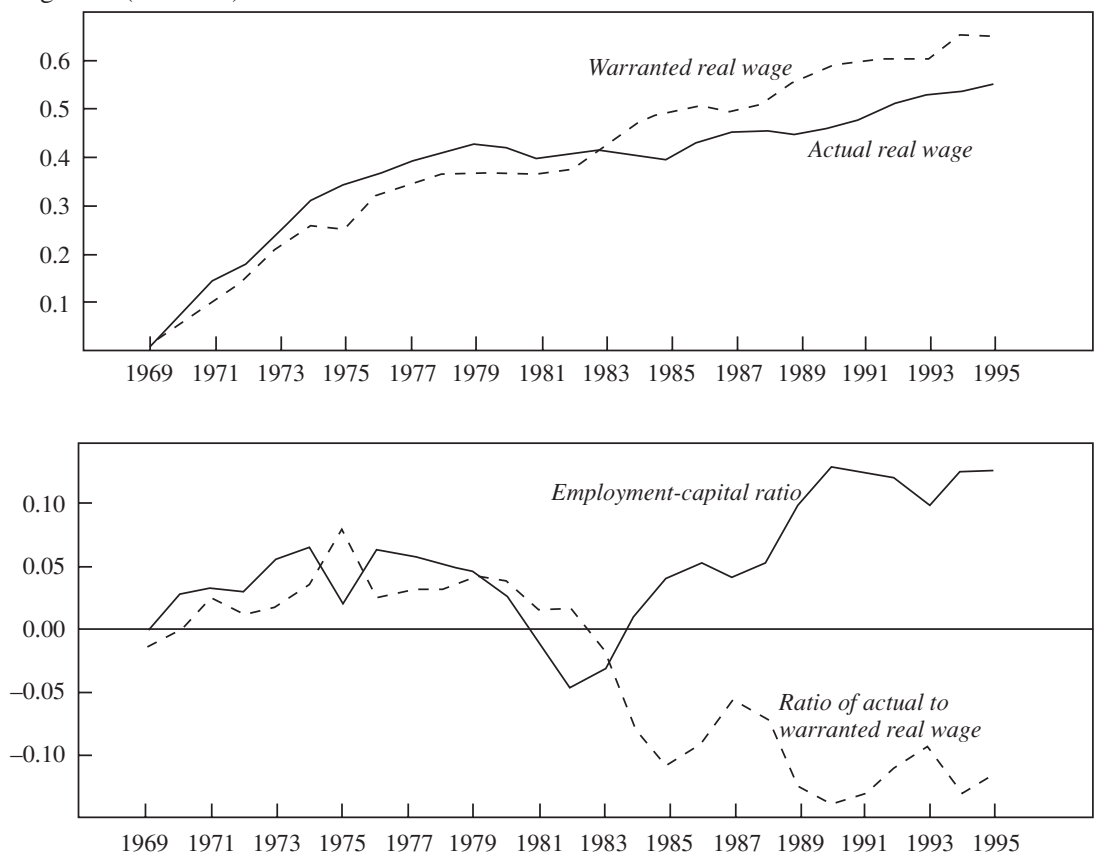

Source: Author's calculations using data from the OECD Business Letter database.

example, figure 3 shows the corresponding time series for France. There, wage moderation (real wages lying below warranted real wages) starts later and has been more limited. There is no evidence of a turnaround in the labor-capital ratio. (The French data end in 1995. Preliminary work with more recent data does show a turnaround, and unemployment has indeed started decreasing.)

All this is good news, as it tells us that the underlying mechanisms that we believe should have been at work have indeed been at work. Wage moderation has led to more employment, more profits, more capital, and eventually more employment. (It also means, however, that the specific mechanism emphasized by the present paper is not the key to the decrease in unemployment in Ireland and the Netherlands. If it were, we would see high wages, not low wages. But I do not think that the authors would push 
Figure 3. France: Actual and Warranted Real Wages and Employment-Capital Ratio, 1969-95
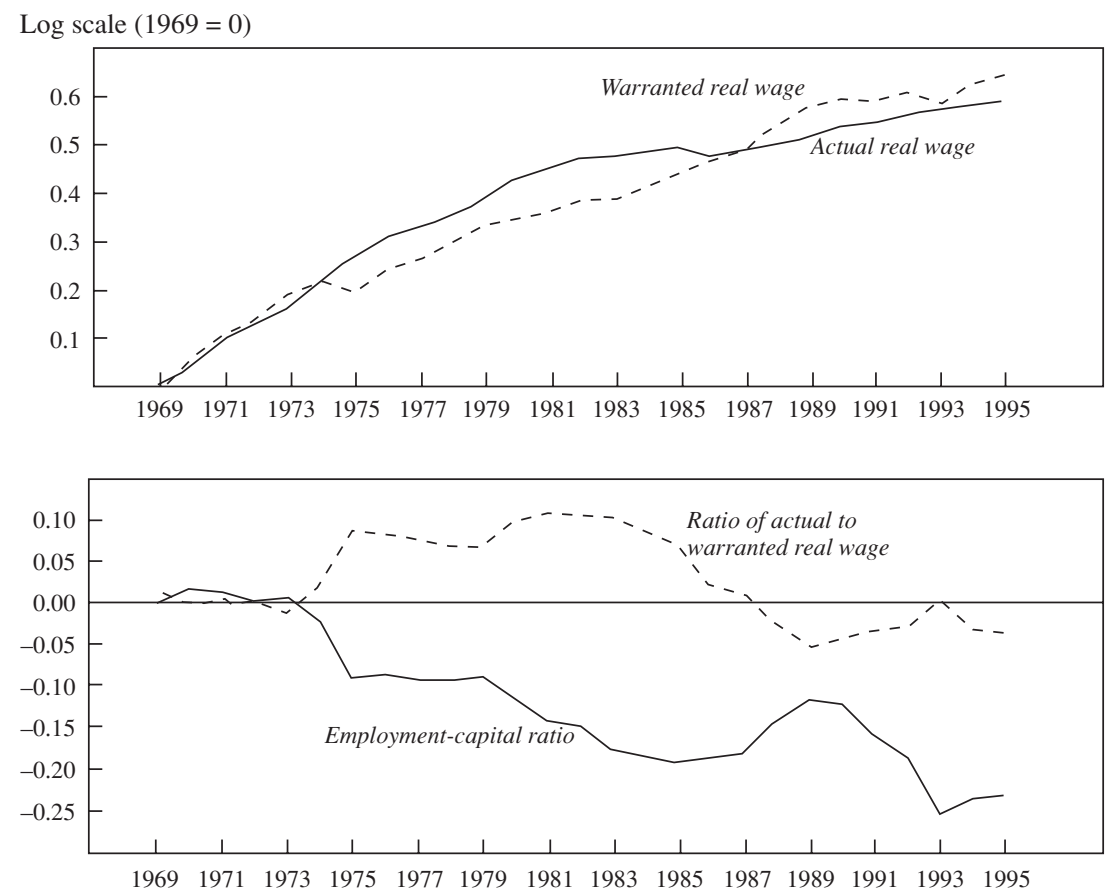

Source: Author's calculations using data from the OECD Business Letter database.

this interpretation anyway, given that the turnaround in both countries dates back to the mid-1980s.) The next step, however, is to go back from wage moderation to more fundamental causes. And there the two countries seem quite different.

In Ireland, the story seems to come from a combination of an unusually high rate of technological progress, on the one hand, and wage moderation coming from the high integration of the Irish and U.K. labor markets, on the other. As can be inferred by comparing the vertical scales in figures 1 and 2, technological progress has been much greater in Ireland; this appears to be due in large part to the direct and indirect effects of foreign direct investment. At the same time, high labor mobility between the United Kingdom and Ireland has limited wage growth in Ireland relative to that in the United Kingdom, where productivity growth has been much 
lower. My reading of the evidence is that this labor mobility, rather than the social pacts signed from 1986 on, is the mechanism behind wage moderation and the Irish miracle. For that reason, it is probably sui generis. One cannot expect, for example, the same degree of wage moderation in other European countries.

The story of the Netherlands is more relevant for other European countries. It is also more confusing. Many explanations have been offered, some of which are wrong. It is not the case, for example, that the fall in unemployment hides a fall in the number of hours worked per worker; the large increase in part-time employment that has indeed taken place in the Netherlands has been associated with a corresponding increase in participation rates. My reading is that wage moderation in the Netherlands is due in large part to social pacts in that country, in particular the 1982 Wassenaar agreement. That agreement is interesting to study. It would seem to focus on all the wrong remedies to reduce high unemployment, from subsidies for early retirement to a shorter workweek. In retrospect, whether or not these measures made sense on their own, they appear to have been the pills that facilitated wage moderation, and which have led to the steady improvement in the labor market since. This makes for a complex story, one that panel data regressions may have a hard time fitting. It coincides, however, with a fairly consistent result of such regressions, including those in table 4 of this paper. That is that coordination of wage negotiations appears to reduce the effect of macroeconomic shocks on unemployment. In the Netherlands, coordination came too late to avoid the increase in unemployment. (Perhaps things had to get very bad in order to trigger such coordination.) But coordination has played a central role in the decline in unemployment.

Christopher A. Sims: This paper takes the stance that unemployment arises from the interaction of the dynamic decisions of workers and firms, and that for both of them these decisions have the nature of investment problems and interact with other dynamic problems, such as saving and investment in physical capital.

I am sympathetic with this stance. Some of its implications are recognized and pursued in the paper, even motivate the paper. The paper emphasizes that changes in interest rates, productivity of capital, productivity of workers, population growth, age distribution of the population, laws regulating labor markets, and prices of capital goods could all be important influences on the unemployment rate. 
But the paper's viewpoint carries other implications that are not so well reflected in the paper. The paper's viewpoint suggests that unemployment need not be monotonically related to welfare and efficiency. As elaborated in Phelps's book Structural Slumps, there are several versions of the theory, all of which imply that there is no reason to expect labor market outcomes automatically to be optimal. ${ }^{1}$ But workers can search for new jobs and firms can invest in training new employees with too much or too little intensity, and their intensity influences the unemployment rate. One can imagine an economy in which innovation is held back by policies that encourage low unemployment rates and low wages. Indeed, there are policies that one expects could keep unemployment low at the expense of cumulating misallocations of labor, so that they generate low current unemployment at the cost of higher future unemployment. The paper disregards these possibilities. It would have been interesting to see some accounting for possible two-way feedback between output per workingage person and the unemployment rate, both in the descriptive statistical analysis and in the theoretical discussion. The paper's apparent presumption that more unemployment is always worse may easily be correct, but it is not obviously correct.

The dynamic theory underlying the paper is inherently multivariate and interactive, with multiple potential sources of change in the unemployment rate. Decisions by firms, reacting to technological change and shifts in demand, can change unemployment. The same is true for decisions by workers, reflecting changes in the age composition and education of the work force and expectations about the future value of implicit wage contracts. Government labor market regulations are an independent source of variation, as are product market regulations, antitrust policy, and trade policy. Sorting out these potential sources of influence to "explain" variations in the observed unemployment rate is a challenging task, and the paper does not face up well to the challenge.

The paper's story about the data is as follows: that a "base" regression equation that in some sense represents the paper's theory worked to explain unemployment over 1960-98; that this equation shows the interaction of variables measuring labor market sclerosis with real macroeconomic variables suggested by the paper's theory; and that the regression results show only a modest role for monetary, as opposed to this paper's dynamic real, influences on unemployment. These results simply update to 
the 1990s work done by Phelps and others earlier. The story goes on to claim that the changes from the 1980s to the 1990s are not well accounted for by the previous empirical formulations, and that the introduction of stock price indices as explanatory variables corrects this problem. This result is taken as evidence in favor of the type of theory of unemployment presented in this paper and in Phelps's previous work.

Although this story about the data could be true, it is not very well supported, for three reasons. Most important, the paper's strategy of letting competing theories be represented informally by variables on the righthand side of single-equation regressions relies on some implicit assumptions and theorizing that would be hard to maintain were they made explicit. The competing theories here are, roughly speaking, a monetary theory, a theory based on labor market institutions, and a productivity theory. None of these theories suggests a single-equation regression as a test bed for the theory. Analysis of the effects of monetary policy now routinely accepts the importance of endogenous reactions of monetary policy to economic disturbances, so that no single variable has a claim to even approximately represent monetary policy. This paper represents monetary policy, and all other nominal demand effects on unemployment, by putting inflation rates or differences of inflation rates on the right-hand side of regressions. Serious modern theories of the effects of monetary policy would not suggest that this is a good measure. And they would suggest that many of the other variables on the right-hand side of the paper's regression equation, including stock prices, would be sensitive to monetary policy.

The representation of labor market institutions is more complex, but subject to the same sort of objection. A set of institutional and labor market policy variables used by previous researchers is introduced and allowed to enter the basic regression as an interaction with "macro" variables, so that the equation is nonlinear. (We are presented the results in two linear regressions, layered on top of each other, so that the statistics associated with the results are hard to interpret.) Surely labor market institutions affect firm profitability, and hence the stock market. Given that the measures we have of labor market flexibility are quite imperfect, it does not make sense to take evidence that stock prices have explanatory power in regressions as evidence for the productivity theory and against the institutional theories.

The general point here is that it is well known that stock prices, like any auction-market asset prices, respond quickly to new information of all 
sorts. Almost any dynamic, stochastic theory of the economy is therefore likely to imply that stock prices have predictive power for almost any important macroeconomic variable. Finding significant coefficients on stock prices in a regression explaining macroeconomic variables therefore hardly ever has much value in discriminating among competing theories, and this paper is no exception.

The paper does not document very well its claim that there was something special about the transition from the 1980s to the 1990s that previous empirical specifications cannot account for. The paper's table 5 does show that the paper's base regression, fit through 1991, does not forecast very well seven years ahead. But this is a dynamic regression with a fairly large coefficient on lagged unemployment. It is quite possible that once we took account of that, and of the fact that the coefficients of the regression are estimated with error, the size of these forecast errors would be unsurprising. The paper also shows that when the variables in the base specification are used, grouped in a few separate regressions, to explain changes in unemployment from the $1980 \mathrm{~s}$ to the $1990 \mathrm{~s}$, the $R^{2} \mathrm{~s}$ are in some (but not all) cases low, and many coefficients are insignificant. But no evidence is presented that this pattern of low $R^{2} \mathrm{~s}$ and insignificant coefficients in predicting crossdecade changes is new to the 1990 s, or that it implies any deterioration in the fit of the original panel data specification of the paper's table 1 .

When stock prices are added to the regressions, they certainly enter significantly, but this is true both in the basic specification (table 1) for 1960-98 and in the regressions explaining the 1980s versus the 1990s. It appears to me that the most reasonable conclusion is that stock prices have long been correlated with changes in unemployment. Certainly some changes in unemployment in the 1990s have been hard to predict, but whether this situation is really different from what has been seen in previous decades remains unclear. And, for the reasons already summarized above, the evidence presented here, particularly the evidence on correlations with stock prices, does little to help us distinguish competing theories of the evolution of unemployment.

The level and persistence of unemployment rates around the world remain poorly accounted for by standard macroeconomic theories. The type of thinking represented by this paper's theory is a good start toward a more useful theory. But bringing this kind of theory into useful contact with the data will require more attention to the link between behavioral theory and econometric specification. 
General discussion: Benjamin Friedman observed that the relationship in the authors' model among the three classes of firms' assets-trained workers, the customer base, and tangible assets - was bound to be a complicated one, possibly involving unequal returns across assets along the adjustment path to a steady state. Even if firms aim to equalize the returns to each asset in equilibrium, they still might be expected to invest in each along different paths, depending on the relation between the speed and the costs of adjustment. Thus the formal model's equilibrium would not necessarily support the idea that firms respond to a favorable shock to productivity growth by adding labor at exactly the same speed as they add to their fixed capital.

Kevin Stiroh observed that the correlation of total factor productivity growth and capital shallowing in some of the countries discussed by Olivier Blanchard in his comment might be a measurement error arising from the lack of quality adjustments to price indexes for high-technology capital goods. Without the kinds of quality adjustments made to U.S. data, real equipment investment would be underestimated and total factor productivity growth correspondingly overestimated. Blanchard responded that he was uncertain about the quality corrections in the data for individual countries, but he reiterated that the available data show capital shallowing in OECD countries in which unemployment has decreased, and capital deepening in countries in which unemployment has increased.

William Nordhaus welcomed the paper's attempt to explore aggregate demand effects but suggested that such an exploration might have usefully gone beyond the analysis of monetary policy that the authors report. An analysis of primary structural surpluses and country-specific export demands would be informative. And although the authors report that a dummy variable for a country staying in the European monetary system during the 1990s was not significant in explaining unemployment, a more careful assessment of exchange rate policy might detect some effect. Nordhaus also noted that stock markets would be expected to exert significant aggregate demand effects through consumption, quite apart from their possible influence through the investment channel, which the paper emphasized. He agreed with Christopher Sims' comment that a correlation of anything with stock market returns is hard to interpret causally because the market is potentially responsive to any shock.

Shang-Jin Wei observed that, important though it is to investigate the impact of institutions on unemployment, there is often little variation in 
the data on which to base an analysis, as the authors had found. He noted that recent examples of large institutional change that had not been exploited by researchers were the introduction of a thirty-five-hour workweek in France, and China's move to a five-day workweek last year. $\mathrm{He}$ suggested that these changes, and earlier ones like the move from a six- to a five-day workweek in the European countries, might provide information on the impact of such changes on unemployment and on the interactions between institutions and shocks. 


\section{References}

Akerlof, George A., William T. Dickens, and George L. Perry. 1996. "The Macroeconomics of Low Inflation.” BPEA, 1:1996, 1-76.

Ball, Laurence 1999. "Aggregate Demand and Long-Run Unemployment." BPEA 2:1999, 189-236.

Blanchard, Olivier. 1997. “The Medium Run.” BPEA 2:1997, 89-141.

Blanchard, Olivier J., and Lawrence Summers. 1986. "Hysteresis and the European Unemployment Problem.” In NBER Macroeconomics Annual, edited by Stanley Fischer. MIT Press.

Blanchard, Olivier, and Justin Wolfers. 2000. "The Role of Shocks and Institutions in the Rise of European Unemployment: The Aggregate Evidence.” Economic Journal 110(March): 1-33.

Bruno, Michael, and Jeffrey Sachs. 1985. Economics of Worldwide Stagflation. Oxford: Blackwell.

Elmeskov, Jorgen, John Martin, and Stefano Scarpetta. 1998. "Key Lessons For Labour Market Reforms: Evidence From OECD Countries' Experience." Swedish Economic Policy Review 5(2): 205-52.

Fitoussi, Jean-Paul. 1996. "Substitutabilities vs. Complementarities between Structural and Macroeconomic Policies." In Macroeconomic Policies and Structural Reform. Paris: Organisation for Economic Co-operation and Development.

Fitoussi, Jean-Paul, and Edmund S. Phelps. 1988. The Slump in Europe: Reconstructing Open Economic Theory. Oxford: Basil Blackwell.

Hoon, Hian Teck, and Edmund S. Phelps. 1992. "Macroeconomic Shocks in a Dynamized Model of the Natural Rate of Unemployment." American Economic Review 82(4): 889-900.

___ 1996. "Payroll Taxes and VAT in a Labor-Turnover Model of the 'Natural Rate.' International Tax and Public Finance 3: 185-201.

_-__- 1997. "Growth, Wealth and the Natural Rate: Is Europe's Job Crisis a Growth Crisis?" European Economic Review 41(3-5): 549-57.

Juhn, Chinhui, Kevin M. Murphy, and Robert Topel. 1991. "Why Has the Natural Rate of Unemployment Increased Over Time?” BPEA, 2:1991, 75-142.

Krugman, Paul. 1994. "Past and Prospective Causes of High Unemployment.” In Reducing Unemployment: Current Issues and Policy Options. Kansas City, Mo.: Federal Reserve Bank of Kansas City.

Layard, Richard, Stephen Nickell, and Richard Jackman. 1991. Unemployment: Macroeconomic Performance and the Labour Market. Oxford University Press.

Madsen, Jakob. 1998. "General Equilibrium Macroeconomic Models of Unemployment: Can They Explain the Unemployment Path in the OECD?" Economic Journal 108(May): 850-67.

Nickell, Stephen. 1998. "Unemployment: Questions and Some Answers." Economic Journal 108(May): 802-16. 
Nickell, S., and R. A. Layard. 1999. "Labor Market Institutions and Economic Performance." In The Handbook of Labor Economics, edited by Orley Ashenfelter and David Card. Amsterdam: North-Holland.

Nickell, Stephen, and Jan van Ours. 2000. "The Netherlands and the United Kingdom: A European Unemployment Miracle?" Economic Policy 30: 135-80.

Organisation for Economic Co-operation and Development. 1982. OECD National Accounts, Detailed Tables, vol. II. Paris. 1987. OECD National Accounts, Detailed Tables, vol. II. Paris. 1998. OECD National Accounts, Detailed Tables, vol. II. Paris.

Phelps, Edmund S. 1994. Structural Slumps: The Modern Equilibrium Theory of Unemployment, Interest, and Assets. Harvard University Press.

-_-_. 1999. "Behind This Structural Boom: The Role of Asset Valuations." American Economic Review, Papers and Proceedings 89: 63-68.

Phelps, Edmund S., and Sidney G. Winter, Jr. 1970. "Optimal Price Policy Under Atomistic Competition." In Microeconomic Foundations of Employment and Inflation Theory, by Edmund S. Phelps and others. Norton.

Phelps, Edmund S., and Gylfi Zoega. 1996. "The Incidence of Increased Unemployment in the Group of Seven, 1970-1994." Discussion Paper 21/96. Birkbeck College.

-_ 1997. "The Rise and Downward Trend of the Natural Rate." American Economic Review, Papers and Proceedings 87: 283-89.

-_-_. 1998. "Natural-Rate Theory and OECD Unemployment." Economic Journal 108(May): 782-801.

Pissarides, Christopher A. 1990. Equilibrium Unemployment Theory. Cambridge, Mass.: Basil Blackwell.

Scarpetta, Stefano. 1996. "Assessing the Role of Labour Market Policies and Institutional Settings on Unemployment: A Cross Country Study." OECD Economic Studies 26(1): 43-98. 
